\title{
A Fused Radar-Optical Approach for Mapping Wetlands and Deepwaters of the Mid-Atlantic and Gulf Coast Regions of the United States
}

\author{
Brian T. Lamb 1,2,*(D), Maria A. Tzortziou ${ }^{1,2}$ (D) and Kyle C. McDonald 1,2,3 (D) \\ 1 Department of Earth and Atmospheric Sciences, The City College of New York, New York, NY 10031, USA; \\ mtzortziou@ccny.cuny.edu (M.A.T.); kmcdonald2@ccny.cuny.edu (K.C.M.) \\ 2 Earth and Environmental Sciences Program, The City University of New York Graduate Center, \\ New York, NY 10016, USA \\ 3 Carbon Cycle and Ecosystems Group, Jet Propulsion Laboratory, California Institute of Technology, \\ Pasadena, CA 91109, USA \\ * Correspondence: blamb@gradcenter.cuny.edu
}

check for updates

Citation: Lamb, B.T.; Tzortziou, M.A.; McDonald, K.C. A Fused Radar-Optical Approach for Mapping Wetlands and Deepwaters of the Mid-Atlantic and Gulf Coast Regions of the United States. Remote Sens. 2021, 13, 2495. https://doi.org/ $10.3390 /$ rs13132495

Academic Editors: Daniel Gann and Jennifer Richards

Received: 5 March 2021

Accepted: 11 June 2021

Published: 26 June 2021

Publisher's Note: MDPI stays neutral with regard to jurisdictional claims in published maps and institutional affiliations.

Copyright: (c) 2021 by the authors. Licensee MDPI, Basel, Switzerland. This article is an open access article distributed under the terms and conditions of the Creative Commons Attribution (CC BY) license (https:/ / creativecommons.org/licenses/by/ $4.0 /)$.
Abstract: Tidal wetlands are critically important ecosystems that provide ecosystem services including carbon sequestration, storm surge mitigation, water filtration, and wildlife habitat provision while supporting high levels of biodiversity. Despite their importance, monitoring these systems over large scales remains challenging due to difficulties in obtaining extensive up-to-date ground surveys and the need for high spatial and temporal resolution satellite imagery for effective space-borne monitoring. In this study, we developed methodologies to advance the monitoring of tidal marshes and adjacent deepwaters in the Mid-Atlantic and Gulf Coast United States. We combined Sentinel-1 SAR and Landsat 8 optical imagery to classify marshes and open water in both regions, with user's and producer's accuracies exceeding $89 \%$. This methodology enables the assessment of marsh loss through conversion to open water at an annual resolution. We used time-series Sentinel-1 imagery to classify persistent and non-persistent marsh vegetation with greater than $93 \%$ accuracy. Nonpersistent marsh vegetation serves as an indicator of salinity regimes in tidal wetlands. Additionally, we mapped two invasive species: wetlands invasive Phragmites australis (common reed) with greater than $80 \%$ accuracy and deepwater invasive Trapa natans (water chestnut) with greater than $96 \%$ accuracy. These results have important implications for improved monitoring and management of coastal wetlands ecosystems.

Keywords: tidal marsh; radar; optical; random forest; Trapa natans; Phragmites australis

\section{Introduction}

Blue carbon ecosystems such as tidal marshes, mangroves, and seagrass meadows, are among the most productive ecosystems on the planet and far surpass all other ecosystems in carbon sequestration on a per-area basis [1-3]. Global mangrove distributions have been effectively mapped, and recently updated, with efforts like the Global Mangrove Watch (GMW) [4,5]. However, recently updated and temporally and spatially harmonized estimates of tidal marsh extent remain poor [6,7]. Further, very few research efforts have attempted to assess marsh vegetation characteristics over large scales, in spite of the important role that marsh vegetation plays in trapping sediments, contributing organic matter to soil carbon stocks, and attenuating flood pulses [8,9]. In this study, we characterized tidal marsh extent and vegetation characteristics for the Mid-Atlantic Coast and Gulf of Mexico (Gulf Coast) of the United States, two regions with a high prevalence of coastal wetlands and high wetland productivity [10]. In addition to mapping wetlands that include marshes and swamps, we also mapped associated deepwater habitats including open water and aquatic beds. We focused our vegetation assessment on the identification of persistent vegetation and non-persistent emergent vegetation in tidal marshes. Persistent vegetation 
maintains significant biomass outside of the growing season while non-persistent vegetation loses the majority of its biomass outside of the growing season due to physical degradation and decomposition.

In tidal marsh systems, the presence of non-persistent emergent vegetation serves as an indicator of tidal freshwater settings where average salinities are below 0.5 parts per thousand (PPT), yet hydrology remains tidally influenced [11]. Thus, the monitoring of tidal freshwater marsh vegetation can provide critical indicators of changing salinity regimes and sea-level rise in coastal regions [11]. Tidal freshwater wetlands have some of the highest levels of productivity and biodiversity found in temperate regions, yet very few remote sensing studies have focused on tidal freshwater wetland monitoring [12]. In assessing overall wetland status, it is critical to not only characterize wetland distributions, carbon dynamics, and hydrologic settings, but ecological function and habitat suitability as well. In addition to human modification, invasive species presence remains a primary factor in reducing wetland ecological function [13]. For this reason, in addition to developing approaches for mapping wetlands and deepwaters and their associated vegetation types, we also used approaches developed in this study to identify common invasive species in coastal wetlands and deepwaters of the eastern United States, including the common reed Phragmites australis (common reed) and Trapa natans (water chestnut).

\subsection{Prior United States Wetlands Mapping Efforts}

In the United States (U.S.), several wetland mapping products exist that provide accurate delineations of coastal wetlands and deepwaters at the national scale. The United States Fish and Wildlife Service (USFWS) National Wetlands Inventory (NWI) is one of the most commonly used wetland products for the conterminous United States (CONUS) and Alaska. The NWI relies on aerial photo interpretation to delineate wetlands and deepwaters using the Cowardin classification scheme $[14,15]$. The NWI is very spatially detailed and provides accurate wetland-upland classifications [16]. In addition to being a stand-alone data product, the NWI is also the source for the U.S. tidal marsh assessment used in the Mcowen global tidal marsh inventory [7] and the Feagan blue carbon gross primary productivity (GPP) product [10]. The NWI errs on the side of being an omissive mapping dataset, meaning there is a high degree of confidence in the identification of NWI mapped wetlands, but wetlands may also be omitted (missed) by the NWI. The omissive nature of the NWI makes it an ideal training data source for satellite image-based wetlands classifications. For instance, the National Landcover Database (NLCD) produced by the Multi-Resolution Land Characteristics (MRLC) Consortium uses NWI as training data for the classification of inland wetlands with Landsat imagery [17,18]. Compared to the NWI's inland wetland mapping accuracy, there have been fewer assessments of NWI tidal marsh mapping accuracy, and NWI tidal marsh locations have been described as "approximate" by the USFWS [19]. For the identification of coastal wetlands, including tidal marshes, the NOAA Coastal-Change Analysis Program (C-CAP) may represent a more robust and accurate dataset than the NWI [20]. Compared to the NWI, C-CAP maps U.S. coastal wetlands at a coarser 30-m spatial resolution using Landsat imagery but possesses specific overall mapping accuracy requirements of $85 \%$ or greater, per-class goal accuracies of $80 \%$, and is updated at five-year intervals, which is more frequent than the NWI [20]. To establish a CONUS mapping of wetlands, the NLCD combines its inland wetland mapping with the coastal wetland mapping of C-CAP. The NLCD and C-CAP match one another in the year of production and five-year update frequency. For the remainder of this manuscript, we refer to the use of NLCD wetland data, noting that NLCD is a direct ingestion of C-CAP for our coastal regions of study. C-CAP produces 1-2-m resolution coastal landcover products in addition to its $30-\mathrm{m}$ product covering all coastal regions of the U.S. However, these 1-2-m C-CAP products have limited coverage, and for our purposes, they lacked coverage in critical study sites in New York, Maryland, and Louisiana and thus were not used. The latest version of the NLCD (and C-CAP) was released for 2016 and the earliest version dates back to 2001 [18]. 
Because tidal marshes are highly dynamic, the five-year temporal fidelity of the NLCD may not be sufficient to resolve short-term changes in the wetlands extent, which can occur on an annual basis. This is particularly true of wetlands losses that occur as a result of coastal degradation by, e.g., extreme or increasingly frequent storm events [21-24]. We specifically sought to address this limitation by using satellite datasets that provide higher effective temporal resolution than aerial photography and Landsat imagery alone. Integration of multi-sensor satellite datasets allowed us to resolve intra-annual wetlands dynamics which provided critical information to our annual wetlands classifications. Having monitoring tools that support the mapping of wetlands vegetation at a one- to twoyear fidelity enables more effective habitat assessments, ecological forecasting, greenhouse gas inventory production, assessment of carbon cycling and storage, and assessment of wetlands migration/loss caused by sea-level rise [24-29].

\subsection{Satellite-Based Wetlands Mapping Background}

In addition to the NWI, NLCD, and C-CAP datasets described in the previous section, many other wetlands classification efforts have relied on aerial photography and Landsat imagery [30-35]. Smaller-scale wetlands mapping studies have also used high spatial resolution (<5-m) satellite imagery (e.g., Quickbird, WorldView, and SPOT) [12,21,36-38]. Although this high spatial resolution satellite imagery provides observations with higher radiometric and spectral resolutions than aerial photography, and higher spatial resolutions than Landsat, the lack of large-scale coverage reduces its utility. The global coverage of Landsat imagery offers a clear advantage over high spatial resolution datasets and the use of coarser 30-m resolution imagery does not significantly impact wetland classification accuracy in most cases [34]. With optical imagery, such as Landsat, Sentinel-2, and MODIS, the computation of vegetation indices (VIs) using visible and near-infrared (VNIR) bands remains extremely effective for the identification of wetlands vegetation [30,39-41]. VNIRbased VIs are among the most useful data layers for classifying different types of wetlands as well [41-43]. The research of Villa et al. (2015 and 2017) demonstrates that such VIs are not only effective for classifying different wetland emergent vegetation types, but separating them from deepwater floating aquatic vegetation $[44,45]$. The use of shortwave infrared (SWIR) bands and indices prove effective for the identification of open water and provide capabilities in identifying inundated wetlands vegetation in certain cases [31,40,46,47].

In wetland systems with sufficiently dense vegetation including high biomass emergent vegetation and woody vegetation, passive optical instruments cannot detect subcanopy inundation. In these cases, active microwave synthetic aperture radar (SAR) systems offer a technical advantage for inundation detection [42,48-56]. However, SAR sensors vary in their relative response to wetland vegetation structure and sub-canopy hydrologic state, depending on wavelength. In emergent wetlands like tidal marshes, C-band SAR signals have been found to interact more strongly with canopy structural components, while longer-wavelength L-band SAR signals interact more strongly with sub-canopy surface hydrologic state $[57,58]$. Novo et al. (2002) found that C-band SAR backscatter was primarily responsive to wetland vegetation leaf shape, while L-band SAR backscatter responses were driven by vegetation stand height variability and overall biomass [59]. Given that a primary research objective of our study was to accurately separate persistent and non-persistent vegetation, variability in C-band backscatter mediated by leaf shape is highly useful since persistent marsh vegetation tends to be erect with thin vertical structures, while non-persistent vegetation tends to be broad-leafed with more horizontal structures [11]. These general structural differences do not differ between tidal wetlands of the Mid-Atlantic and Gulf Coast [11,60]. Further, because non-persistent vegetation loses its leaf structures outside of the growing season, this likely has a non-trivial impact on C-band SAR scattering response as well. 
Despite the utility of C-band SAR in identifying vegetation structure and phenology, until the launch of the Sentinel-1 SAR satellites by the European Space Agency (ESA) in 2014, C-band SAR availability was limited compared to optical imagery in terms of revisit and operating mode consistency. With the Sentinel-1A SAR satellite, many regions of the coastal U.S. are imaged with a consistent operating mode nearly every 12 days, acquiring both $\mathrm{VV}$ and $\mathrm{VH}$ polarization imagery, which provides relative assessments of surface and volume scattering, respectively. This presents numerous opportunities for the assessment of vegetation structure in wetlands and deepwater ecosystems based on time-series approaches. However, to this point, the use of time-series Sentinel-1 SAR has been applied to wetlands classifications $[43,61,62]$ and the identification of inundation patterns [62-64], with limited research focused on the characterization of wetlands-deepwater vegetation structure and phenology. Clear opportunities exist in this research area given the demonstrated C-band SAR emergent vegetation structural response $[57,59,65]$, demonstrated success with time-series optical approaches [44] in wetlands-deepwater vegetation classifications, and successful studies applying L-band SAR for wetland biomass characterizations $[66,67]$.

\subsection{Research Objectives and Rationale for Satellite-Based Wetlands Mapping}

In this study, we combined time-series Sentinel-1 C-band SAR vegetation structural and phenological identifications with established optical approaches to classify wetlands and deepwater systems using SAR-optical fusion methods, culminating in a two-tier classification scheme applied to Mid-Atlantic and Gulf Coast study regions. SAR-optical fusion has been demonstrated to be an effective mapping approach for wetlands and deepwater systems ranging from the boreal to tropical and across a range of continents and coastal-inland gradients [41-43,55,61,62,68,69]. Of the established SAR-optical fusion classification approaches, random forest (RF) remains one of the most successful and widely-implemented [41-43,68,70-72]. RF is a non-parametric machine learning approach incorporating multiple decision trees, and iteratively selecting optimal decision tree combinations, thus forming a forest-like structure [72]. We used an RF classifier for the first tier of our classification scheme, hereafter termed the level-1 classification.

RF-based wetland classifications are most commonly performed on a per-pixel basis [41,42,70,71]. Recently, Mahdianpari et al. (2019) found increases in wetland classification accuracy by using an object-based RF classifier [43]. However, the per-pixel RF classification approach has several advantages relevant to our study, the foremost of which is the computational efficiency of per-pixel classifications. This is an important consideration in assessing the feasibility of large-scale mapping efforts. Further, the per-pixel RF classification scheme provides readily interpretable pixel-level agreement assessments between the wetlands-deepwater RF classification (level-1) and structural and phenological identification of vegetation using time-series SAR by isolating temporal variability for a given pixel, rather than assessing combined spatial and temporal variability over two separate classification schemes.

For the second classification tier, termed the level-2 classification, we explicitly sought to use a rule-based decision tree classification scheme for vegetation identification, as this approach has been demonstrated computationally efficient and ideal for explicit communication of scientific findings in remote sensing studies [56,57]. While Lamb et al. (2019) found high accuracy levels (>95\%) for wetland vegetation classifications using time-series SAR imagery with an RF classier, this current study seeks to improve on those efforts with the use of an explicitly defined rule-based approach for vegetation identification. Because rule-based decision tree classifications do not readily integrate object-based approaches, we elected to keep both the level-1 RF classifications and level-2 rule-based classifications as per-pixel implementations. 


\section{Materials and Methods}

\subsection{Study Sites}

Prior to carrying out classification efforts, we established target wetland study sites, including general study sites and intensive study sites. The general study sites are largescale regions covering broad areas, while the intensive study sites cover smaller regions and have associated multi-season ground surveys. The motivation in the selection of study sites was to apply classification techniques over a wide variety of coastal wetland systems. In the Mid-Atlantic region, general study sites include the Hudson River (NY-NJ), Housatonic River/Long Island Sound (CT-NY), Delaware River (NJ-DE), Patuxent River (MD), and Choptank River (MD). The Gulf Coast general study sites included the Sabine River (TX), the Wax Lake Delta (LA), and Mississippi River wetlands including the Breton Sound and the Bird's Foot Delta (LA). These systems vary considerably in terms of geomorphology, hydrology, and salinity gradients. General study sites are shown in Figure 1.
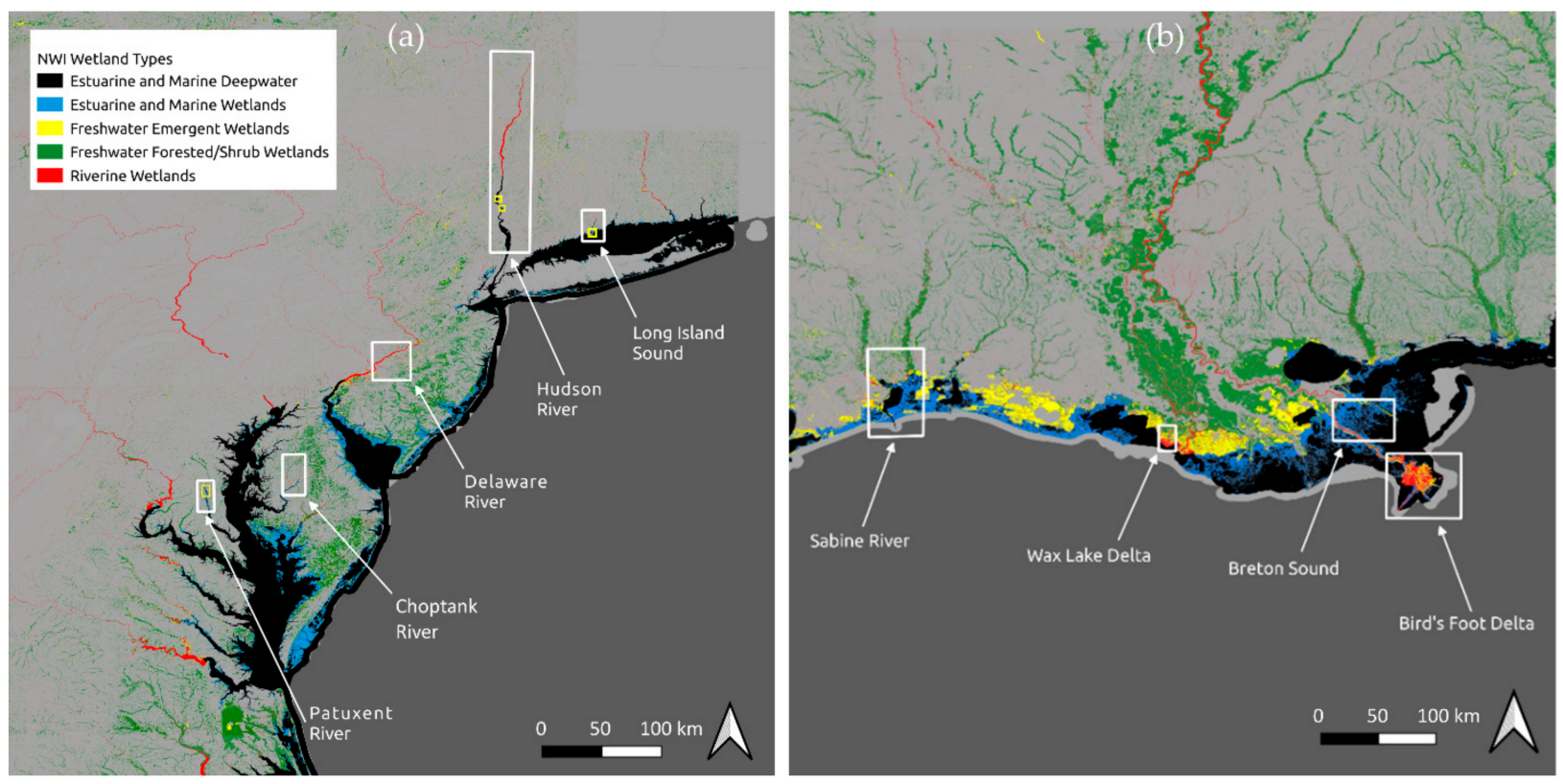

Figure 1. General study sites in the Mid-Atlantic (a) and Gulf Coast (b) shown in white rectangles. Intensive study sites for the Mid-Atlantic region are also shown as yellow rectangles within general study sites. These intensive study sites are depicted in more detail in Figure 2 as well. From north to south, intensive study sites are as follows: Beacon Bridge wetlands and Constitution Marsh in the Hudson River, Wheeler Marsh in the Long Island Sound, and Jug Bay wetlands in the Patuxent River.

We selected the Jug Bay Wetlands Sanctuary as the intensive study site in the Patuxent River, the Wheeler Marsh system as a Long Island Sound intensive study site, and Beacon Bridge wetlands (not an official name) and Constitution Marsh sites as Hudson River intensive study sites (all shown in Figure 2). Jug Bay possesses a mix of persistent and non-persistent emergent vegetation, typical of tidal freshwater marshes throughout both the Gulf and Atlantic Coasts [11,60,72]. Wheeler Marsh is a mesohaline brackish system characterized by persistent emergent vegetation and a high frequency and magnitude of tidal inundation relative to other sites. This hydrologic variability ( $>2 \mathrm{~m}$ for regular tidal cycle) poses the potential for confusion with vegetation phenological variability when characterizing wetlands with time-series SAR imagery, and this is specifically addressed in our study. The Hudson River wetlands are tidal freshwater and possess a mixture of persistent and non-persistent vegetation types. The final datasets used for analyses are a blend of our own ground surveys, wetland surveys from other studies, the NWI, and our analysis of recent aerial photography. At Jug Bay, we developed a final dataset from a survey by Swarth et al. (2013) [73], which represents a more accurate classification than the NWI, that in certain areas incorrectly classified the non-persistent emergent vegetation 
species Nuphar lutea (N. lutea) as either persistent emergent tidal marsh or aquatic bed dominated deepwaters (as shown in Figure 2). In addition to non-persistent N. lutea, the final Jug Bay dataset also includes persistent Typha spp., and semi-persistent Zizania aquatica (Z. aquatica) vegetation types. At Constitution Marsh, a 2007 New York State Tidal Wetlands Inventory (NYS-TWI) covering the Hudson River Estuary (HRE) was used to provide more detailed vegetation assessments than the NWI [74]. In the Beacon Bridge wetlands, we used NWI and also note areas of confirmed Trapa natans (T. natans) expansion based on our ground surveys and suspected T. natans based on 2017 aerial photo identification. Overall, the NWI accurately classified T. natans as deepwater aquatic beds in Hudson River sites but omitted areas of recent expansion. For Wheeler Marsh, we use NWI boundaries, but have updated the wetland classes based on ground survey confirmation shown in parentheses in Figure 2. For Wheeler Marsh, the "low marsh" class represents sparse Spartina alterniflora (S. alterniflora) and mudflat, "mid marsh" represents dense S. alterniflora, and "high marsh" represents Spartina patens and Distichlis spicata mix. The NWI E2SS1P class is incorrect and represents an estuarine system with scrub-shrub vegetation, however, our site visits indicated this NWI boundary is best represented by an estuarine high marsh class as shown in the site photos in Figure 3g. Additional intensive study site vegetation photo examples are also shown in Figure 3. Please see Table 1 to reference NWI classes in Figure 2 and associated vegetation types when NWI classification is correct.

Table 1. NWI code definitions for common wetland and deepwater classes used in this study. The first column, NWI Code, is defined according to the Cowardin classification hierarchy in columns 2-8. Common species (right-most column) shows examples of vegetation common to a given NWI Code.

\begin{tabular}{|c|c|c|c|c|c|c|c|c|}
\hline NWI Code & System & Subsystem & Class & Subclass & Water Regime & $\begin{array}{c}\text { Special } \\
\text { Modifiers }\end{array}$ & $\begin{array}{c}\text { Water } \\
\text { Chemistry }\end{array}$ & $\begin{array}{l}\text { Common } \\
\text { Species }\end{array}$ \\
\hline E2EM1P & E-estuarine & 2-intertidal & EM-emergent & 1-persistent & $\begin{array}{l}\text { P-irregularly } \\
\text { flooded }\end{array}$ & - & - & Spartina patens \\
\hline E2EM1N & E-estuarine & 2-intertidal & EM-emergent & 1-persistent & $\begin{array}{l}\text { N-regularly } \\
\text { flooded }\end{array}$ & - & - & $\begin{array}{l}\text { Spartina } \\
\text { alterniflora }\end{array}$ \\
\hline E2EM2N & E-estuarine & 2-intertidal & EM-emergent & $\begin{array}{l}\text { 2-non- } \\
\text { persistent }\end{array}$ & $\begin{array}{l}\text { N-regularly } \\
\text { flooded }\end{array}$ & - & - & Nuphar lutea * \\
\hline E2EM5P & E-estuarine & 2-intertidal & EM-emergent & 5-phragmites & $\begin{array}{l}\text { P-irregularly } \\
\text { flooded }\end{array}$ & - & - & $\begin{array}{c}\text { Phragmites } \\
\text { australis }\end{array}$ \\
\hline E2SS1P & E-estuarine & 2-intertidal & SS-shrub/scrub & 1-broad leafed & $\begin{array}{l}\text { P-irregularly } \\
\text { flooded }\end{array}$ & - & - & Iva frutescens \\
\hline E2EM1P6 & E-estuarine & 2-intertidal & EM-emergent & 1-persistent & $\begin{array}{l}\text { P-irregularly } \\
\text { flooded }\end{array}$ & - & 6-Oligohaline & Leersia oryzoides \\
\hline E2EM1N6 & E-estuarine & 2-intertidal & EM-emergent & 1-persistent & $\begin{array}{l}\text { N-regularly } \\
\text { flooded }\end{array}$ & - & 6-Oligohaline & Scirpus spp. \\
\hline E2EM1Nd6 & E-estuarine & 2-intertidal & EM-emergent & 1-persistent & $\begin{array}{l}\text { N-regularly } \\
\text { flooded }\end{array}$ & d-Ditched & 6-Oligohaline & Typha spp. \\
\hline E2EM5Pd6 & E-estuarine & 2-intertidal & EM-emergent & 5-phragmites & $\begin{array}{l}\text { P-irregularly } \\
\text { flooded }\end{array}$ & d-Ditched & 6-Oligohaline & $\begin{array}{c}\text { Phragmites } \\
\text { australis }\end{array}$ \\
\hline E1ABL6 & E-estuarine & 1-subtidal & AB-aquatic bed & - & L-subtidal & - & 6-Oligohaline & Trapa natans \\
\hline E1UBL6 & E-estuarine & 1-subtidal & $\begin{array}{l}\text { UB- } \\
\text { consolidated }\end{array}$ & - & L-subtidal & - & 6-Oligohaline & $\mathrm{mud} / \mathrm{sand}$ \\
\hline PEM1 & P-palustrine & - & EM-emergent & 1-persistent & - & - & - & Carex spp. \\
\hline PEM2 & P-palustrine & - & EM-emergent & $\begin{array}{l}\text { 2-non- } \\
\text { persistent }\end{array}$ & - & - & - & $\begin{array}{l}\text { Pontederia } \\
\text { cordata }\end{array}$ \\
\hline PEM5 & P-palustrine & - & EM-emergent & 5-phragmites & - & - & - & $\begin{array}{l}\text { Phragmites } \\
\text { australis }\end{array}$ \\
\hline R1ABT ** & R-riverine & 1-tidal & AB-aquatic bed & - & $\begin{array}{l}\mathrm{T}- \\
\text { semipermanently } \\
\text { flooded }\end{array}$ & - & - & Sagittaria spp. \\
\hline R1AB3V ** & R-riverine & 1-tidal & AB-aquatic bed & $\begin{array}{l}\text { 3-rooted } \\
\text { vascular }\end{array}$ & $\begin{array}{l}\text { V-permanently } \\
\text { flooded }\end{array}$ & - & - & Zostera marina \\
\hline R1AB3T ** & R-riverine & 1-tidal & AB-aquatic bed & $\begin{array}{l}\text { 3-rooted } \\
\text { vascular }\end{array}$ & $\begin{array}{l}\mathrm{T}- \\
\text { semipermanently } \\
\text { flooded }\end{array}$ & - & - & Ruppia martima \\
\hline R1AB4V ** & R-riverine & 1-tidal & AB-aquatic bed & $\begin{array}{l}\text { 4-floating } \\
\text { vascular }\end{array}$ & $\begin{array}{l}\text { V-permanently } \\
\text { flooded }\end{array}$ & - & - & $\begin{array}{l}\text { Eichhornia } \\
\text { crassipes }\end{array}$ \\
\hline
\end{tabular}



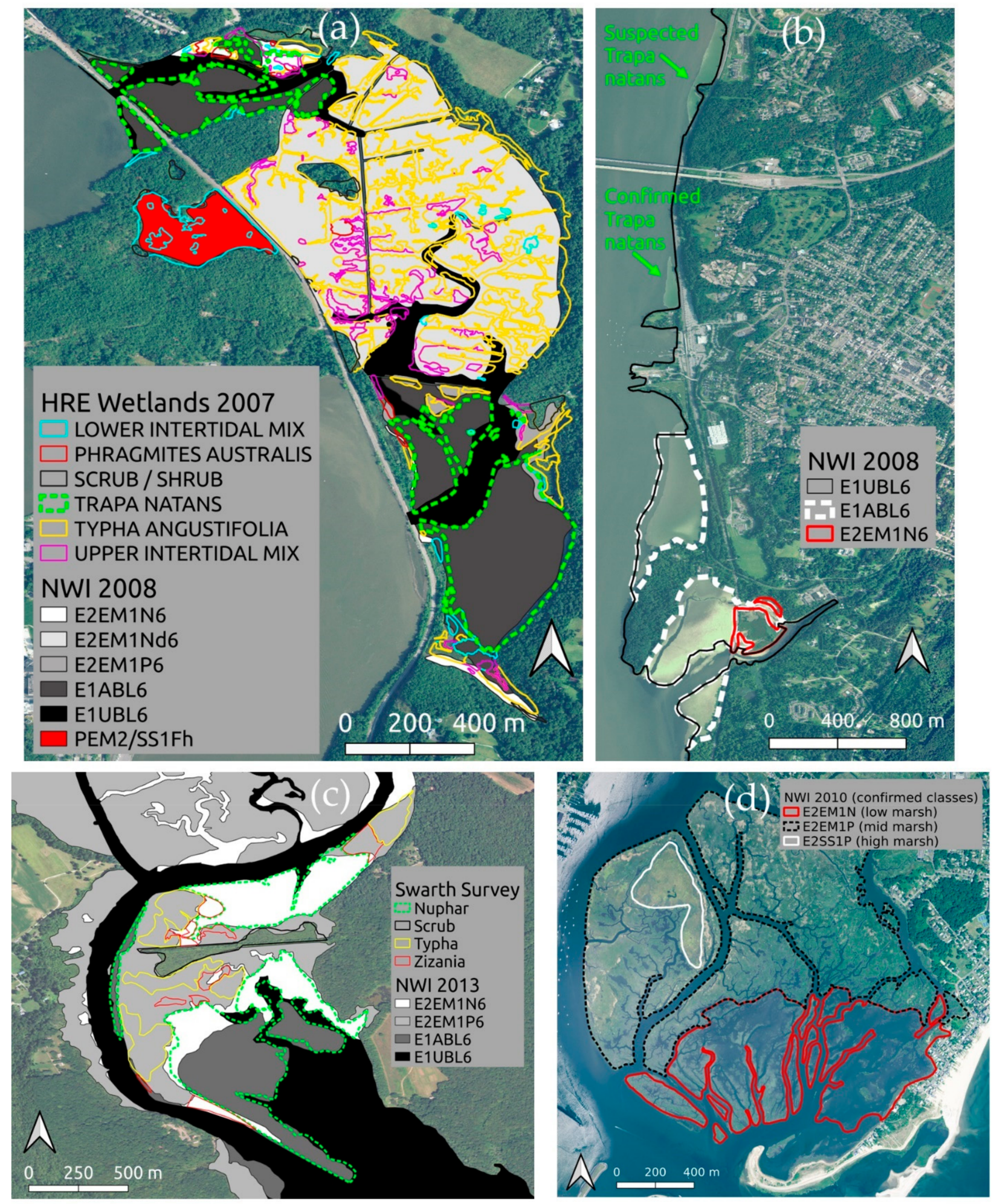

Figure 2. Intensive study sites with final wetland vegetation inventory datasets; Constitution Marsh (a), Beacon Bridge wetlands (not an official name) (b), Wheeler Marsh (c), and Jug Bay (d). Wheeler Marsh ground-confirmed classes are shown in legend parentheses. Note there are several cases where NWI classifications do not match more detailed wetland inventories or ground surveys. Detailed descriptions of NWI wetlands codes are provided in Table 1. 

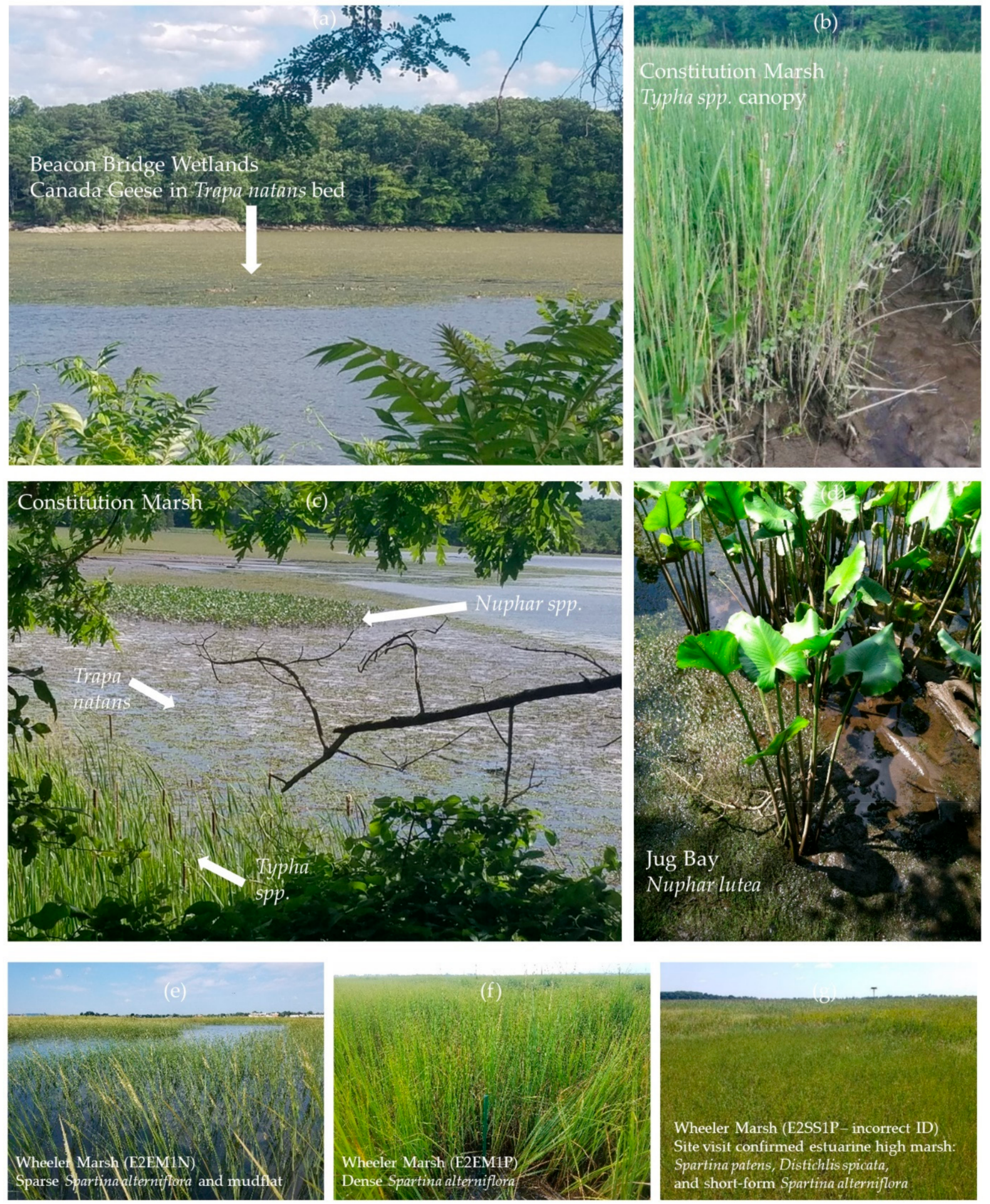

Figure 3. Site photo examples of wetland vegetation for the Beacon Bridge wetlands (a), Constitution Marsh (b,c), Jug Bay (d), and Wheeler Marsh (e-g). Note in many of the photos connected surface waters and aquatic beds are shown adjacent to wetlands. Constitution Marsh presents a clear demonstration of the fine elevation gradients that zonate moderate elevation marsh wetland vegetation like Typha spp. from low elevation marsh wetland vegetation like Nuphar spp. from floating aquatic deepwater vegetation like T. natans. Wheeler Marsh shows a common zonation of persistent vegetation for an Atlantic U.S. brackish tidal marsh complex. While the NWI E2EM1N and E2EM1P classes are roughly correct for Wheeler Marsh, the E2SS1P class in panel $g$ is most accurately classified as the E2EM1P class for estuarine emergent high marsh. Note that these photos correspond to the intensive study sites in Figure 2. 


\subsection{Satellite Image Assembly and Selection Rationale}

Sentinel-1A C-band SAR and Landsat 8 optical/IR imagery were initially evaluated for application to wetlands vegetation characterization. Landsat 8's Operational Land Imager (OLI) instrument acquires 30-m resolution imagery over seven visible, nearinfrared, and shortwave infrared bands at a 16-day revisit. After initial testing of opti$\mathrm{cal} /$ IR imagery, we focused this time-series analysis on Sentinel-1 C-band SAR imagery due to its more frequent 12-day revisit (when considering cloud impacts on optical imagery), lack of atmospheric impacts, high spatial resolution (10-m), and enhanced capabilities in characterizing vegetation structural phenology. We used Google Earth Engine (GEE) for initial image processing in this time-series assessment [75]. Prior to ingestion into the GEE environment, Sentinel-1 SAR ground range detected (GRD) imagery was processed by GEE developers using ESA's SNAP toolbox using a standardized processing sequence of updating image orbit file, GRD image border noise removal, thermal noise removal, radiometric calibration, and geometric terrain correction (orthorectification) (https:/ / developers.google.com/earth-engine/guides/sentinel1, accessed on 2 June 2020). From 2017-2019, Sentinel-1A imagery was acquired over our study sites with a 12-day revisit in an interferometric wide (IW), dual polarimetric operating mode (VV, $\mathrm{VH})$.

We evaluated Sentinel-1 SAR backscatter for all intensive study site wetland vegetation classes (shown in Figure 2) between 2017 and 2019. GEE was used to extract spatial mean backscatter for each class and to track changes from 2017 to 2019 at a 12-day resolution (Sentinel-1A revisit time). To assess the impact of water level variability as a confounding factor in satellite assessment of wetland vegetation properties, water level observations were acquired over Wheeler Marsh and Jug Bay with Onset HOBO U20L water level sensors that were deployed for several months in 2018 and 2019, respectively. These data were then used to calibrate the nearest tide gauge water levels to estimated in-wetland water levels for 2017-2019. Water level time-series for Wheeler Marsh and Jug Bay wetland sites were matched with Sentinel-1 overpasses and corresponding spatial mean backscatter timeseries for each vegetation class to assess the influence of both hydrology and vegetation phenology on SAR backscatter response. The average tidal range of Wheeler Marsh is approximately twice that of Jug Bay ( $>2-\mathrm{m}$ vs. $\sim 1-\mathrm{m}$ ), allowing assessment of SAR backscatter response for tidal wetlands with different hydrological characteristics.

After performing this time-series assessment, we processed imagery using GEE for the purpose of mapping emergent wetlands for the Gulf and Mid-Atlantic Coasts, and to assess the global applicability of this classification method. Although we focused our timeseries assessment on Sentinel-1 SAR imagery, our preliminary evaluations demonstrated the importance of optical imagery for characterizing vegetation greenness during the growing season. To assess vegetation greenness, we used the Normalized Difference Vegetation Index (NDVI), which remains one of the most well-known and effective indices for assessing the presence of vegetation and vegetation greenness, and can assess vegetation biomass in certain instances [76,77]. NDVI and NDVI variants have been demonstrated as especially useful in assessing marsh vegetation greenness and canopy closure $[30,39,40]$. Informed by these findings, we chose to include an NDVI summer temporal median (June through August) layer in our classifications. Summer NDVI was selected as this period is most likely to provide separation of vegetated wetlands and aquatic beds from open water, which was a critical requirement of our study. The use of a temporal median NDVI computation was selected over a temporal mean to prevent biases due to errors from the incomplete cloud and cloud shadow masking and other artifacts. The summer temporal median NDVI layer was computed from Landsat 8 OLI surface reflectance, cloud-masked imagery in GEE [78,79].

Time-series Sentinel-1 imagery was demonstrated to be critical for wetland vegetation assessment, thus several layers were included in our classifications (see Results Section 3.1 for further justification). Additionally, we included the Shuttle Radar Topography Mission (SRTM) Digital Elevation Model (DEM) in our classifications as DEMs have been shown to consistently improve wetland classification accuracy to a greater degree than SAR or optical 
imagery as wetlands occupy low gradient regions, and coastal wetlands occupy a narrow range of elevations as well $[42,71,80]$. Stacking these different data layers culminated in a SAR-optical-DEM stack consisting of Sentinel-1 VV annual mean, VH annual mean, VV annual standard deviation (SD), VV spring mean, VV summer mean, VV fall mean, Landsat 8 summer median NDVI, and the Shuttle Radar Topography Mission (SRTM) DEM. This image stack was used for both the level-1 classification of wetlands and deepwaters and level-2 classifications of vegetation characteristics. Separate image stacks were generated for the Mid-Atlantic and Gulf Coast regions.

\subsection{Level-1 Classification of Wetlands and Deepwaters}

The objective of the level-1 classification was to map tidal wetlands of the Mid-Atlantic and Gulf Coast United Sates using supervised classification approaches. We used the random forest (RF) classifier for this purpose [72]. For the RF classifications, we parameterized the classifier with 500 trees which Lamb et al. (2019) found ideal for achieving accurate wetlands classifications while considering trade trade-offs with asymptotic limits in error reduction and increasing computational demands with a greater number of trees [72]. The level-1 classification identifies open water, estuarine emergent wetlands, palustrine emergent wetlands, Phragmites australis (P. australis)-dominated emergent wetlands, and woody wetlands in addition to several upland classes including urban, barren, grass, agriculture, shrubs, and forest. Following Lamb et al. (2019), we created a merged training-validation dataset by combining the NWI with the 2016 NLCD and selecting training points only where the classes matched (e.g., NLCD herbaceous wetland code 95 must match one of NWI estuarine emergent classes like E2EM1P, E2EM1N to produce a valid training point) [42]. Classes of non-wetland landcover were selected directly from the 2016 NLCD. The generated training-validation dataset consisted of ten million points. We reduced this dataset to approximately 400,000 training-validation points by performing two random samples with approximately half of the points coming from a stratified random sample with an equal number of points per cover class, and the other half coming from a random sample. This culminated in a final training-validation dataset that weighted class prevalence while preserving a baseline representation of uncommon classes. The aforementioned NLCD training-validation layer was generated in GEE by exporting NLCD layers from 2016 along with the respective SAR-optical-DEM image stacks for the Mid-Atlantic and Gulf Coast regions. This approach ensured that training-validation layers and the satellite image stacks were geo-registered. We used the R programming language 'Random Forest' package to perform supervised RF classifications of the SAR-optical-DEM stack with the training-validation dataset [72,81]. Classification accuracy was assessed using both confusion matrices and post-classification layer importance assessments.

\subsection{Level-2 Classification of Wetlands and Deepwater Vegetation}

The objective of the level-2 classification was to develop a rule-based approach employing decision tree and thresholding to (i) identify persistent versus non-persistent vegetation within the emergent wetlands and deepwaters identified in the level-1 classification and (ii) separate non-persistent emergent vegetation from non-persistent floating aquatic vegetation. Lamb et al. (2019) demonstrated that Sentinel-1A VV backscatter annual standard deviation (SD) was one of the most important image layers to separate non-persistent $N$. lutea from all other wetland vegetation (both woody and persistent emergent) at the Jug Bay study site when using a supervised random forest classification (overall classification accuracy $>95 \%$ ) [42]. However, this prior mapping effort did not develop rule-based approaches applicable across multiple wetland systems and regions, nor did it provide a comparison between emergent wetland non-persistent vegetation and floating aquatic deepwater non-persistent vegetation. Here, we included N. lutea and T. natans dominated sites to determine if both can be identified as a single non-persistent class, then further classified as emergent versus floating non-persistent vegetation based on the sensitivity of C-band SAR backscatter to differences in biomass. The general processing steps that 
include both the level-1 classification and general description of the level-2 classification are shown in Figure 4. Figure 4 also includes general modifications that were made to classifications including masking to open water in cases where pixels had very low NDVI values and $\mathrm{VH}$ annual mean backscatter values.

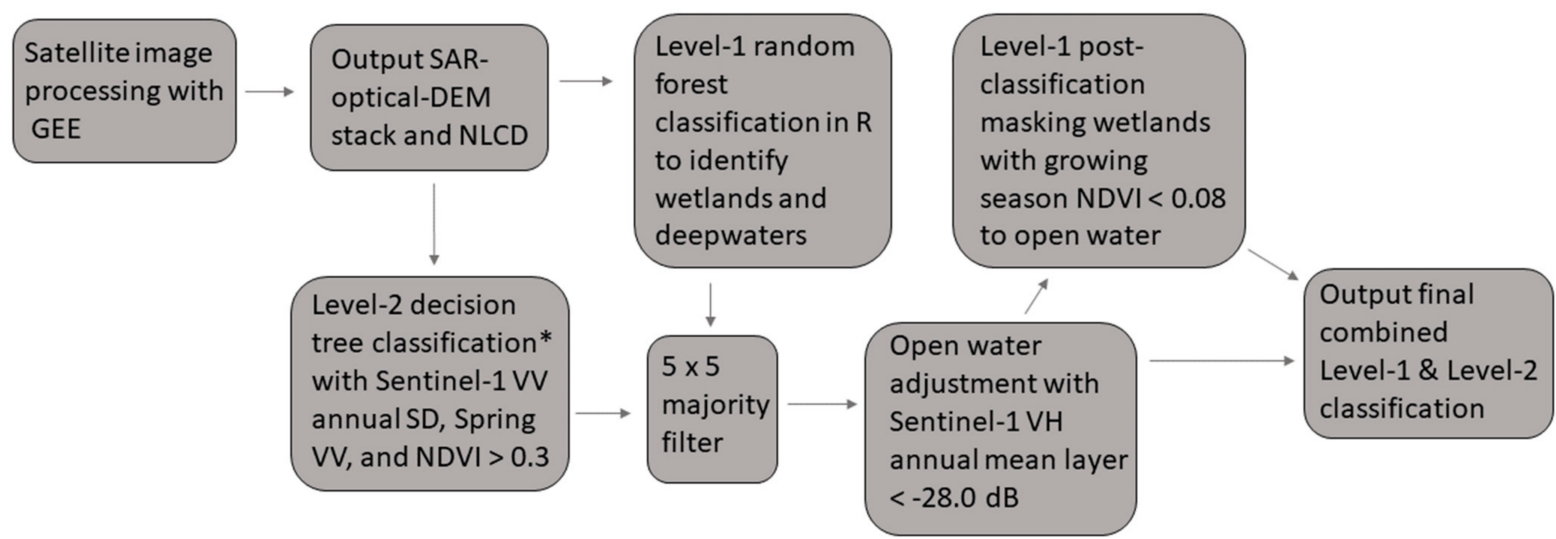

Figure 4. Schematic of image processing, classification, and post-classification adjustments. * Level-2 decision tree classification final derivation is depicted in the following section (Figure 5).

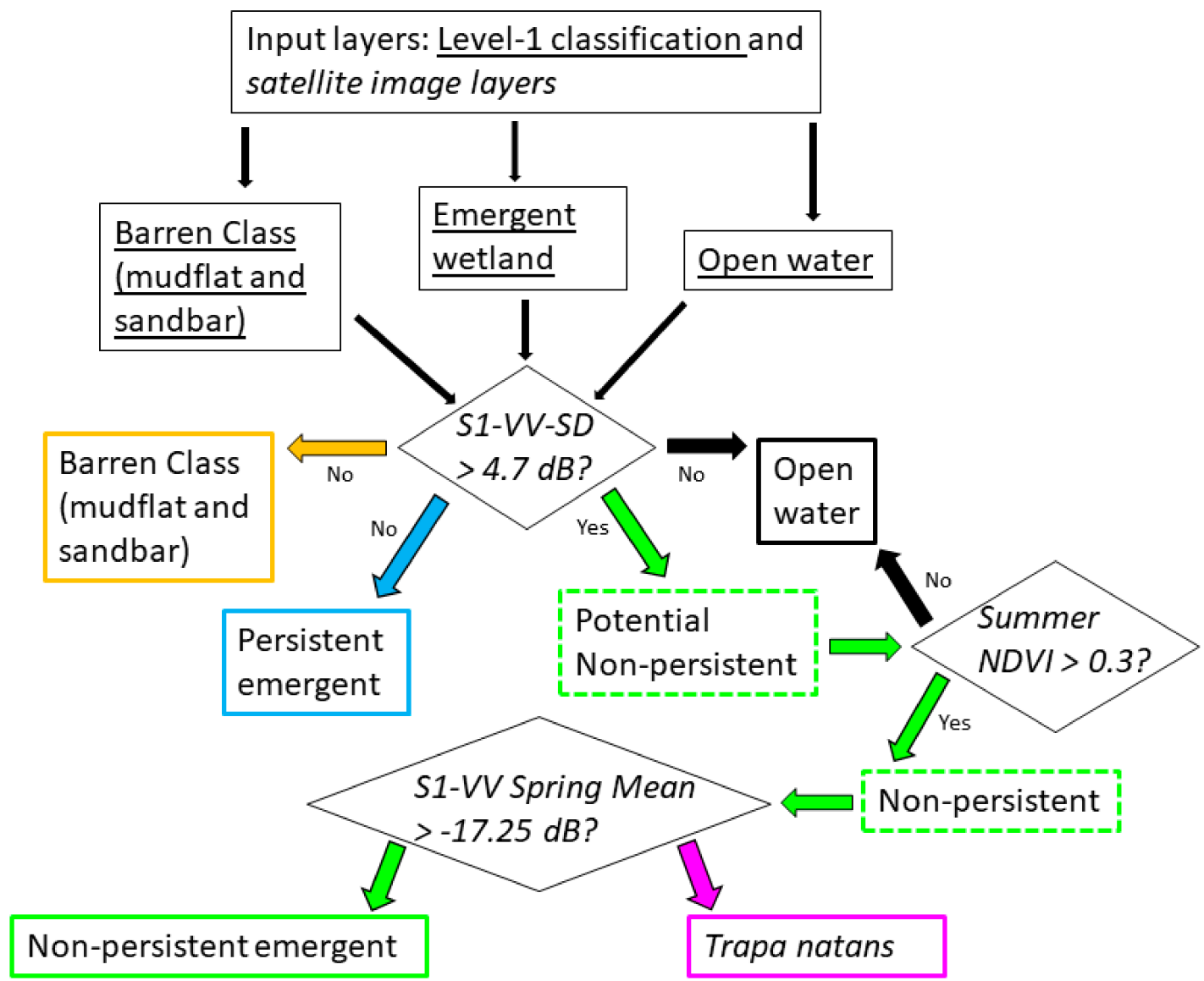

Figure 5. Final level-2 classification for the Mid-Atlantic for 2017. The Gulf Coast level-2 classification utilizes the same methodology but does not separate between aquatics (e.g., T. natans) and non-persistent emergents. This level-2 classification modifies the existing level-1 classification (shown as underlined text in rectangles) and uses satellite layers (italicized text in diamonds) to classify non-persistent emergent and T. natans. The original level-1 classes are preserved where they do not meet level-2 vegetation classification criteria. The colors on the level-2 classification schematic correspond to classification map colors in Results Sections 3.3 and 3.4. 
We used the Sentinel-1 time-series assessment (with results shown in Sections 3.1 and 3.2) to derive a level-2 decision tree classification scheme based on empirically demonstrated differences between vegetation classes. For all vegetated classes, a summer median NDVI > 0.3 was used as this has been demonstrated as an effective threshold for identifying minimally vegetated regions [77]. We then developed a rule to split persistent and non-persistent vegetation based on applying a threshold of $4.7 \mathrm{~dB}$ to Sentinel- 1 annual SD imagery which was demonstrated to completely separate persistent and non-persistent vegetation types (see Results Section 3.2). Last, we separated non-persistent emergent vegetation from $T$. natans by applying a $-17.25 \mathrm{~dB}$ threshold to Sentinel-1 spring VV imagery. Use of the Sentinel-1 annual SD imagery in separating persistent and non-persistent vegetation was demonstrated in Lamb et al. (2019). The use of the Sentinel-1 spring VV image threshold is a new approach that is justified by the fact that $T$. natans may not develop significant above-water structures resulting from leaf elongation until July [82], while non-persistent emergent species generally develop such structures in May [11,72]. The justification for applying this threshold and others is further demonstrated in the time-series analysis in Results Section 3.1. The full description of level-2 classification scheme is provided in Figure 5 which includes details on how the level-1 classification is used as an input to the level-2 classification.

\subsection{Study Site-Based Classification Performance Assessment}

Level-2 classification results were evaluated using independent datasets at three study sites. We also evaluated the level-1 classification using the independent datasets for a validation additional to the RF classification accuracy assessment. For this independent evaluation, we used the Hudson River Submerged Aquatic Vegetation (HRSAV) dataset produced by the Hudson River National Estuarine Research Reserve, New York State Department of Environmental Conservation, and the Cornell Institute for Resource Information Services as an external validation source for our T. natans classification efforts in the Hudson River [83]. The HRSAV does not map emergent wetlands, unlike the $2007 \mathrm{New}$ York State Tidal Wetlands Inventory, but does assess T. natans distributions, with the most recent HRSAV release in 2018. The HRSAV is a shapefile polygon-based dataset derived from manual digitization of aerial photography with a minimum polygon generation size of $5-\mathrm{m}^{2}$, aggregated to a $60-\mathrm{m}^{2}$ minimum size delineation in the final dataset. We used the HRSAV polygons to assess occurrences of our level-2 identified T. natans aquatic beds and to compare HRSAV identified T. natans to our level-1 classification which we found sometimes classified T. natans beds as open water, mudflats, and even emergent wetlands.

An independent evaluation dataset derived from manual digitization of 2017 summer National Aerial Imagery Program (NAIP) imagery [84] was used to evaluate level-1 and level-2 classification performance in mapping emergent wetlands in the Choptank River. The boundaries of persistent and non-persistent vegetation were digitized based on the NAIP imagery and results were compared to level-1 and level-2 classifications. Given that our digitization process was similar to that of the HRSAV dataset, minimum mapping units can be expected to be of a similar order.

The NWI dataset was used to evaluate level-1 and level-2 classification performance in the Wax Lake Delta. Although NWI data was used for training the level-1 classification, the dataset we used in the Wax Lake Delta is still considered independent because it is from the riverine NWI class. This class was excluded in the level-1 classification to enable mapping of wetland systems based on vegetation community composition and salinity rather than the location in a riverine setting. The NWI data for the Wax Lake Delta was updated in 2017 and includes four riverine NWI classes. Because the classification efforts in the Gulf Coast mapped a general non-persistent class rather than splitting between estuarine emergent and floating aquatic non-persistent, the general non-persistent class could include Potamogeton nodosus, Nelumbo lutea, Sagittaria spp., in addition to a number of other species [85]. The NWI features a target minimum mapping unit of 0.5 acres, 
although we have found the detail level of the NWI to be far finer in terms of wetland features resolved.

All three independent performance validation datasets (HRSAV, NAIP, and NWI) were shapefile-based datasets, buffered inward by $30-\mathrm{m}$ to reduce the influence of edges and mixed pixels in assessing the performance of the $30-\mathrm{m}$ level- 1 and level- 2 classifications. The even smaller area of the NAIP-based evaluation dataset for the Choptank River prohibited the use of a buffer after initial testing. After shapefile processing and evaluation were completed, shapefile polygons were used to extract pixels from the level-1 and level-2 classification rasters with the $\mathrm{R}$ programming language. Percent occurrence between the independent validation datasets and corresponding classifications were then assessed as a means of accuracy assessment (e.g., the percentage of level-2 classified T. natans pixels overlapping T. natans polygon area in the HRSAV dataset). The level-1 classification was also assessed in this manner.

\section{Results}

\subsection{Study Site Assessments}

Prior to carrying out level-1 and level-2 classifications, we assessed spatial mean Sentinel-1A SAR backscatter time-series for wetland vegetation classes within three of the Mid-Atlantic intensive study sites shown in Figures 1 and 2. Both VV and VH polarized time-series backscatter were assessed (shown as different panels for each study site in Figures 6-8). The three Wheeler Marsh NWI classes corresponding to S. alterniflora and mudflat, dense S. alterniflora, and high marsh, respectively exhibit temporal backscatter variability driven primarily by inundation state (Figure 6). This is evidenced by correspondence with water level observations, although directional responses do differ between different vegetation types and radar polarizations. The Typha spp. time-series at Jug Bay also show a response to the hydrologic state, especially in the fall season. However, in contrast to the Wheeler Marsh time-series, Typha spp. exhibits a consistent decrease in backscatter during summer. This likely has to do with the pronounced structural changes that occur in Typha canopies transitioning between growing and non-growing seasons. The Jug Bay time-series (Figure 7) provides the first indication of the ability to distinguish between persistent and non-persistent vegetation, as $N$. lutea shows a clear backscatter increase corresponding to emergence timing in late May. This emergence timing is conspicuously present for both VV and VH polarizations in all three years from 2017 to 2019. The Jug Bay time-series also indicates that Z. aquatica, commonly known as wild rice, exhibits backscatter phenology intermediate to Typha spp. and N. lutea. This finding is expected given that the phenology of $Z$. aquatica can be accurately approximated as semi-persistent. This species loses a significant portion of biomass at the end of the growing season, while the remaining vegetation structures (often stems) form a horizontal mat on the marsh platform. In contrast, N. lutea loses almost all above-ground biomass, which explains why outside of the growing season, $N$. lutea exhibits backscatter almost identical to that of open water. A similar non-persistent backscatter signature is observed in the T. natans time-series at Constitution Marsh (Figure 8). The timing of the T. natans emergence lags N. lutea by a few months (late May vs. mid-July). The findings of this time-series analysis served as the empirical basis for satellite image layer selection, described in the following section. 
(a)

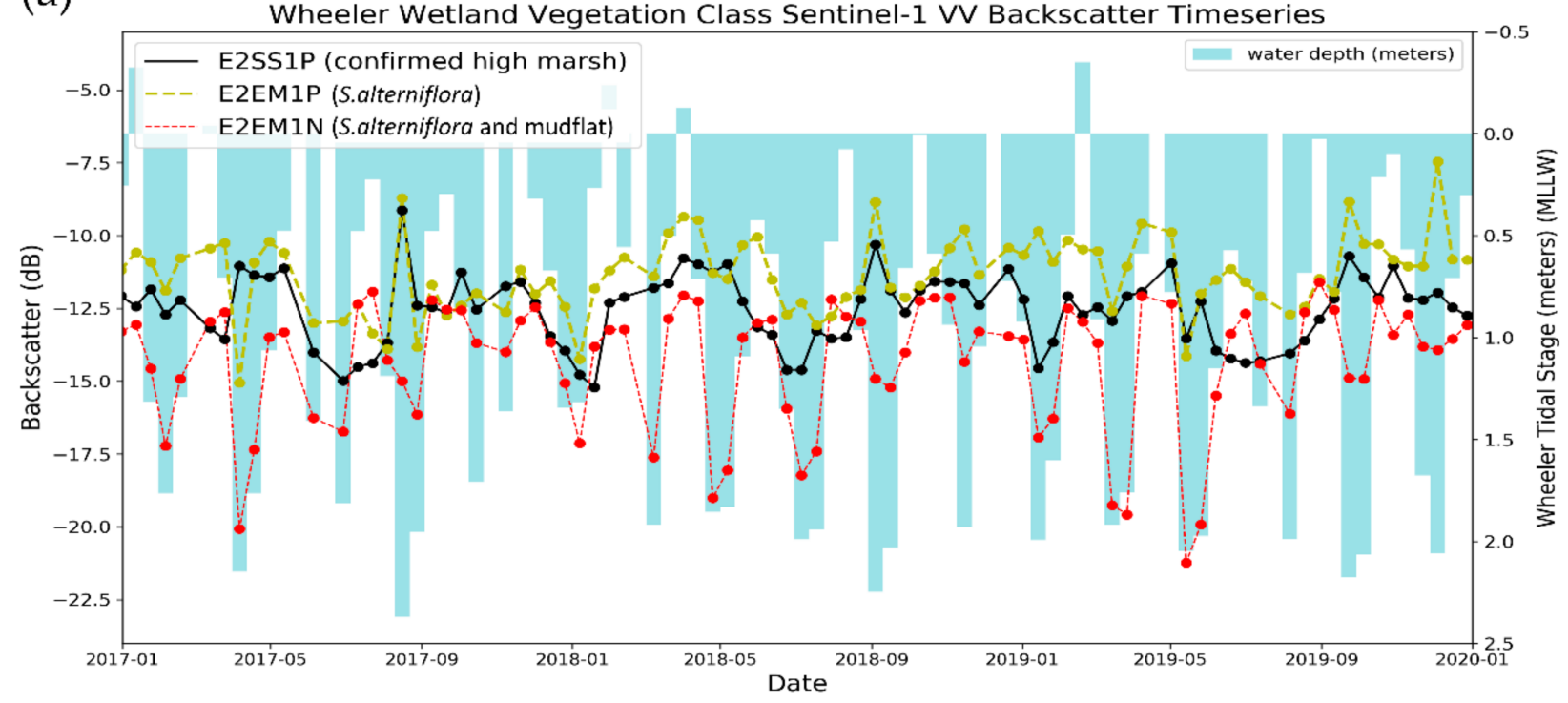

(b)

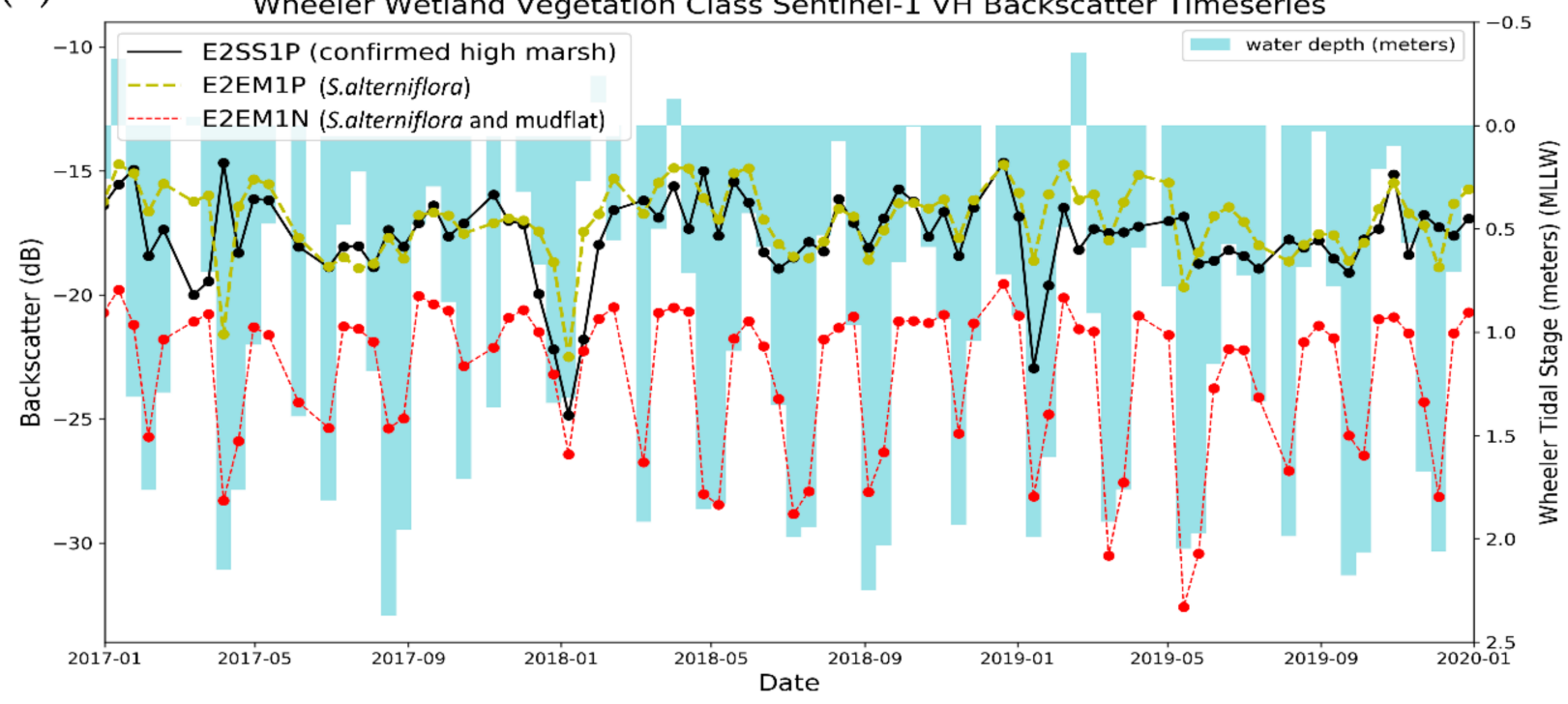

Figure 6. Wheeler wetland vegetation class Sentinel-1 VV and VH polarized backscatter time-series from 2017-2019 in (panels (a) and (b), respectively). Dates are shown in numeric year-month format. Water depth (in meters) is the NOAA tide gauge at Bridgeport (ID: 8467150) calibrated to in-marsh water level changes observed with Onset HOBO sensors from August 2018 to December 2018. Calibrations include time and water depth adjustments. E2EM1N (red dotted series) represents a low elevation portion of the wetland complex with sparse S. alterniflora and mudflat backscatter series. E2EM1P (gold dashed series) represents middle elevation marsh with dense S. alterniflora. E2SS1P (black series) is a high marsh dominated by Spartina patens, Distichlis spicata, and short-form S. alterniflora. For both E2EM1P and E2SS1P, some P. australis is present along wetland-open water and wetland-upland edges. 
(a)

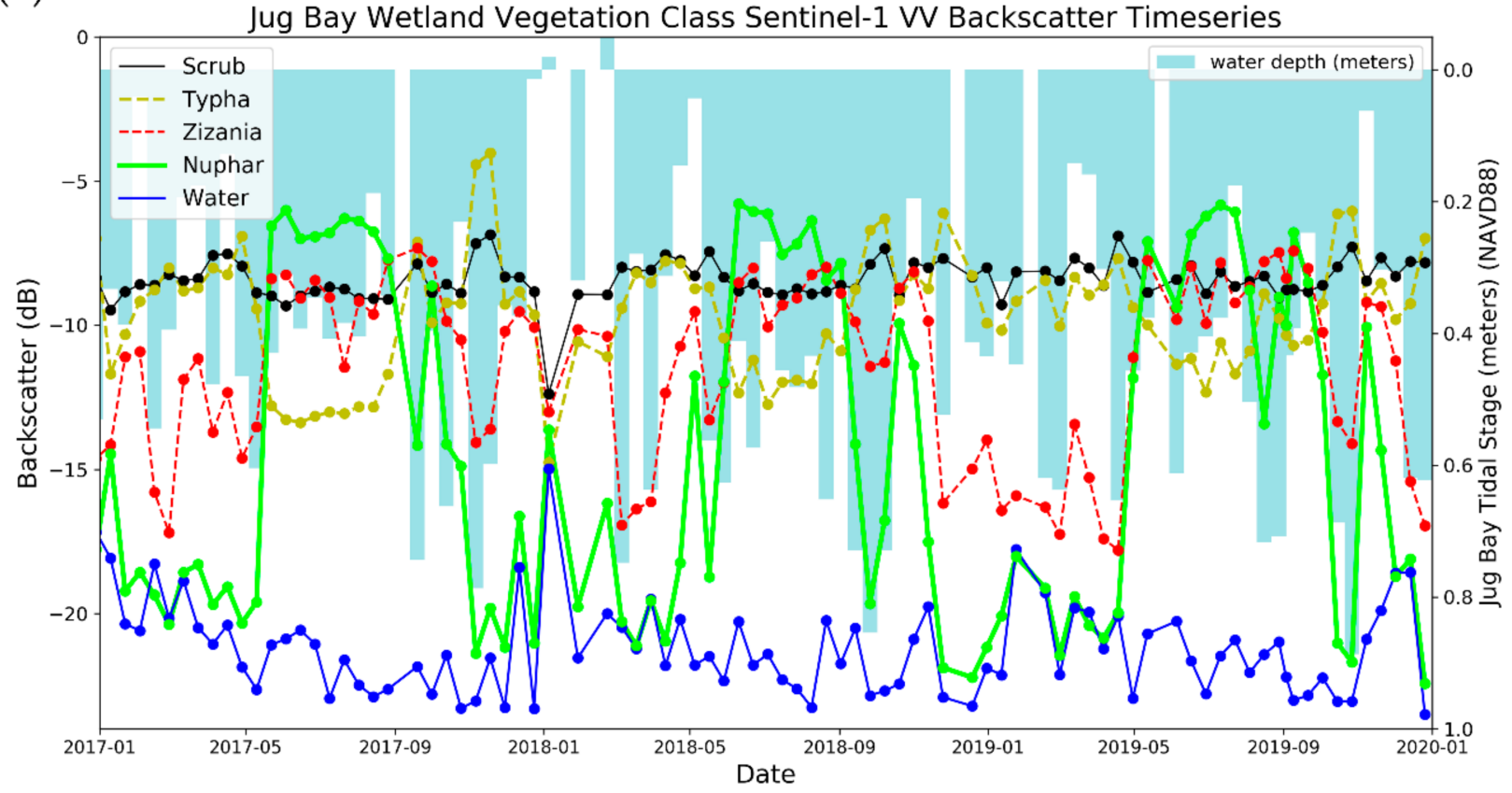

(b)

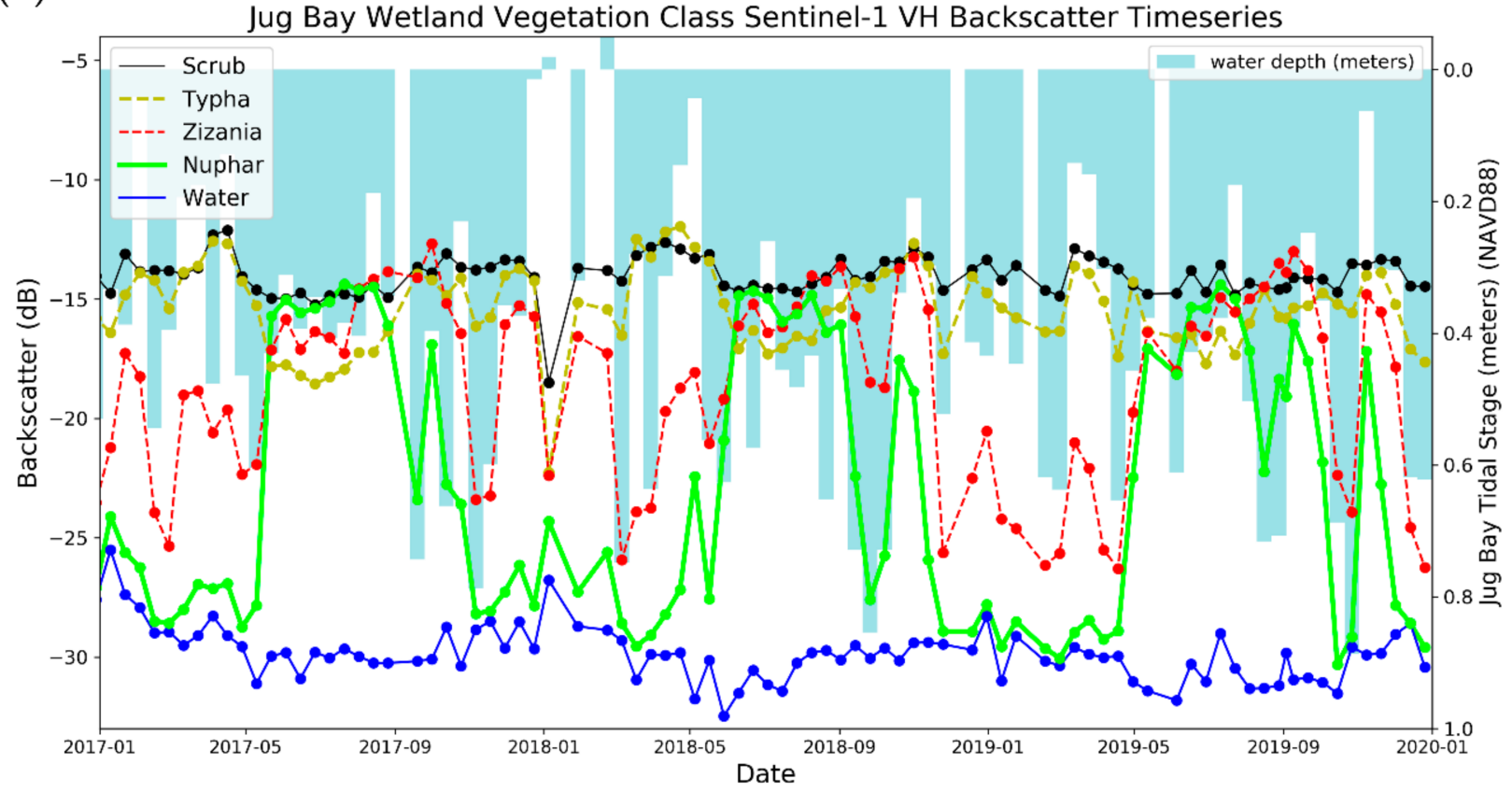

Figure 7. Jug Bay wetland vegetation class Sentinel-1 VV and VH polarized backscatter time-series from 2017-2019 (panels (a) and (b), respectively). Dates are shown in numeric year-month format. Water depth (in meters) is the NOAA tide gauge at Solomon's Island (ID: 8577330) calibrated to in-marsh water level changes observed with Onset HOBO sensors from October 2019 to December 2019. Calibrations include time and water depth adjustments. All series represent spatial mean backscatter from Jug Bay wetland classes originally published in Swarth et al. (2013) and updated in Lamb et al. (2019). The wetlands classes are as follows: solid black series = shrub-scrub, dashed gold series = Typha spp., red dashed series = Zizania aquatica, solid green series = Nuphar lutea, solid blue = open water. 
(a)

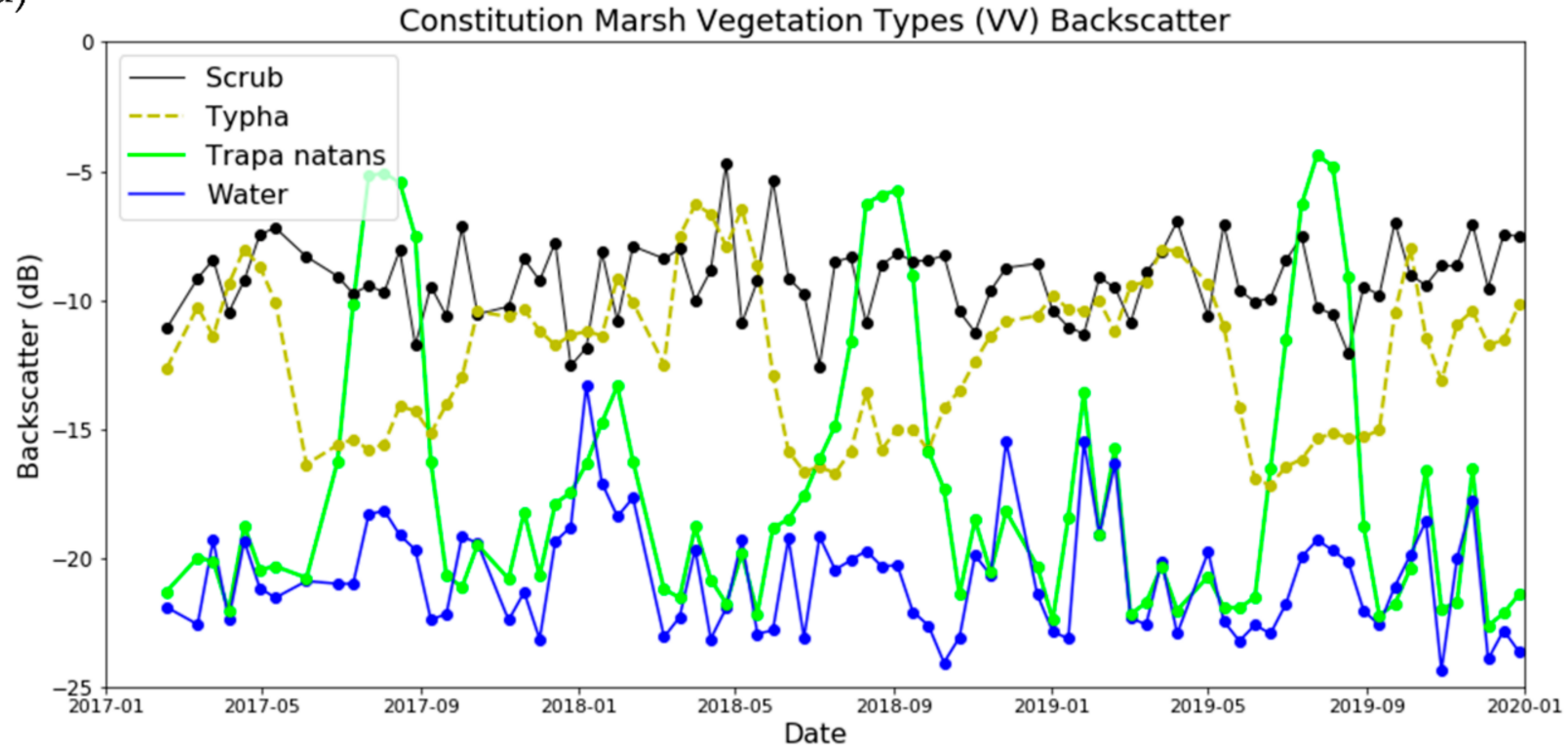

(b)

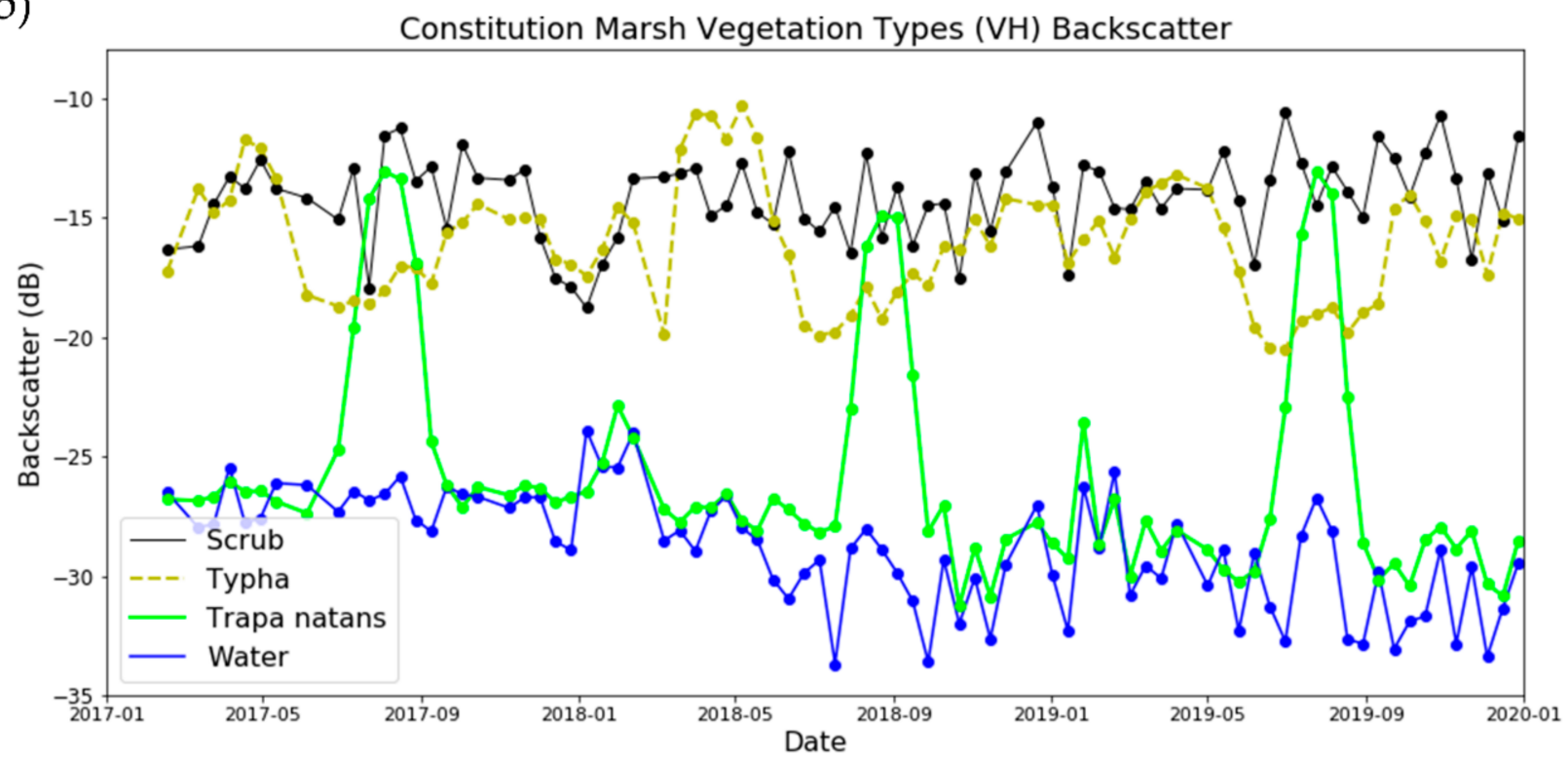

Figure 8. Constitution Marsh Sentinel-1 VV and VH polarized backscatter time-series from 2017-2019 (panels (a) and (b), respectively). Dates are shown in numeric year-month format. The wetlands and deepwater classes are as follows: solid black series $=$ shrub-scrub, dashed gold series = Typha spp., solid green series $=$ Trapa natans, solid blue = open water. 


\subsection{Assessment of Sentinel-1 Imagery for Level-2 Vegetation Classification}

The high levels of backscatter variability tracking the growth phenology of the nonpersistent vegetation classes (Figures 6-8) facilitated the temporal reduction of the SAR dataset by computing the annual mean and standard deviation (SD) layers for Sentinel-1 $\mathrm{VV}$ and $\mathrm{VH}$ polarization imagery time-series. For all non-persistent vegetation, the VV polarized backscatter exhibited higher peaks in the summer, and generally higher SD overall compared to $\mathrm{VH}$ polarized backscatter (Figures 6-8). For this reason, we utilized annual SD from VV polarized imagery for vegetation characterization rather than annual SD from VH polarized imagery. After observing high levels of spatial variability in 2017 annual SD from VV polarized imagery (hereafter referred to as VV-SD) comparing persistent and non-persistent vegetation types, we evaluated separability between the vegetation classes within each target wetland site used in the time-series analysis by extracting all VV-SD pixels for each wetland vegetation class. We then examined distributions to determine if a rule-based decision tree approach could be applied to split persistent and non-persistent emergent classes (Figure 9). We found that thresholding can effectively separate persistent and non-persistent vegetation using the VV-SD layer at a threshold of $4.7 \mathrm{~dB}$ (green horizontal line in Figure 9). A separate threshold of $-17.25 \mathrm{~dB}$, applied to temporal mean imagery from VV polarization for the spring season (15 April 2017 to 15 June 2017) (hereafter referred to as VV-spring mean), allowed separation between T. natans and non-persistent emergents (Figure 10). These results informed our final derivation of the level-2 classification shown in Methods Section 2.4 and Figure 5.

Wetland Vegetation Classes at Wheeler Marshes (w), Jug Bay (jb), Hudson River (h)

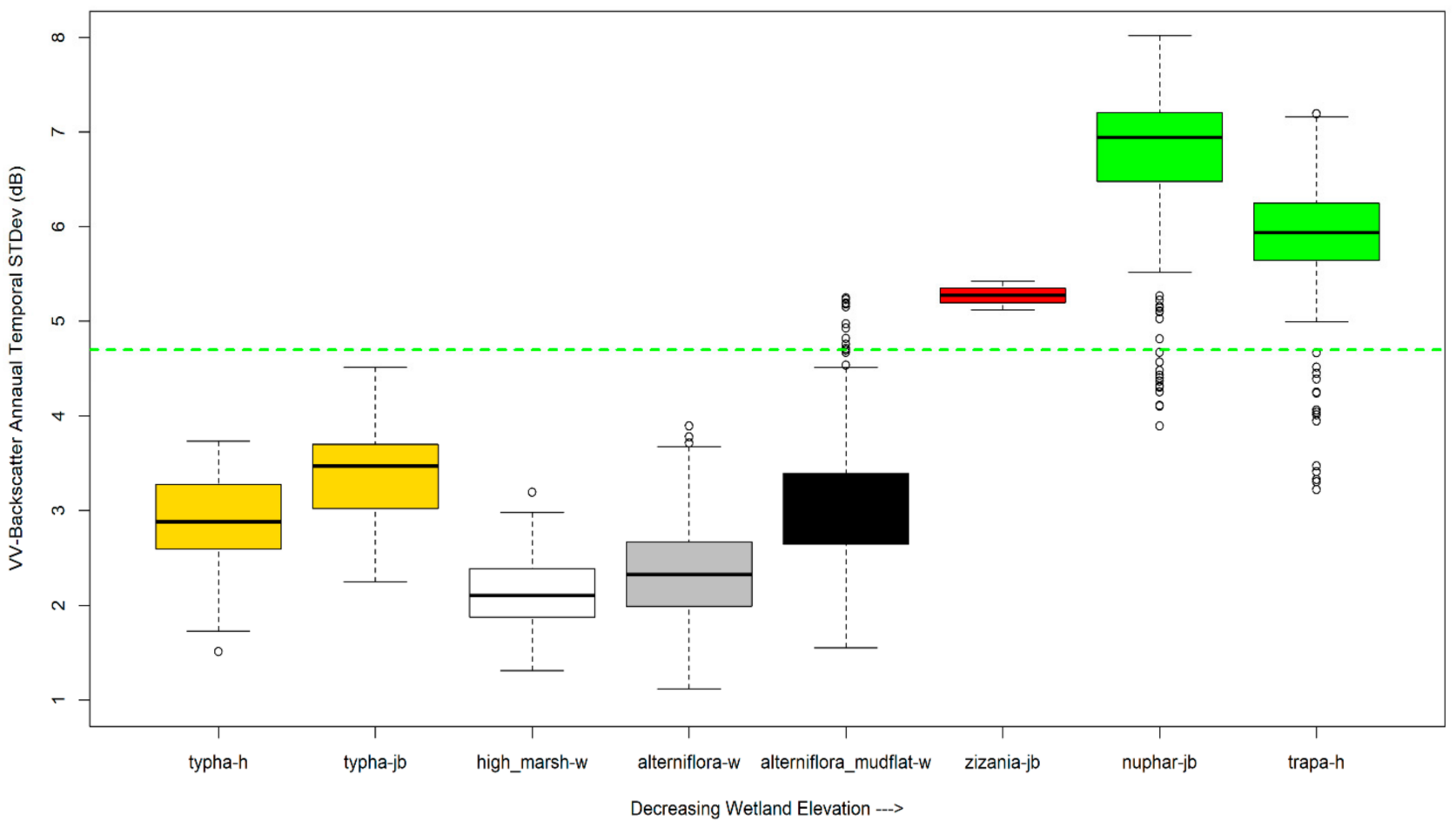

Figure 9. 2017 Sentinel-1 VV annual standard deviation (VV-SD) pixel values by wetland vegetation class at Wheeler Marshes (w), Jug Bay (jb), and Hudson River (h) sites. For box labels, the first term represents wetland vegetation type and the second term is the location (e.g., "typha-h" is Typha spp. from Constitution Marsh in the Hudson River). All boxes represent VV-SD extraction for the wetland vegetation boundaries/polygons shown in Figure 2 that were also used for time-series spatial mean backscatter computation in Figures 6-8. Note that colors also correspond to vegetation type in Figures 6-8, except for Wheeler Marsh where grayscale box colors represent elevation gradient. Note threshold of $4.7 \mathrm{~dB}$ threshold separates persistent and non-persistent vegetation (horizontal dashed green line). 


\subsection{Level-1 Classification Results and Accuracy Assessment}

Level-1 classifications were performed separately for the Mid-Atlantic and Gulf Coast regions. Performance accuracy was quantitatively assessed via confusion matrices (Tables 2 and 3) and also post-classification variable importance assessment (Tables 4 and 5) as outputs from the RF classification process. In addition to providing a regional scale classification as shown in Figure 11, we also demonstrate wetland classification performance over general study sites in the Hudson River, Housatonic River, Delaware River, Patuxent River, and Choptank River (sub-panels a-e). In part, these riverine regions were selected for performance assessment as they contain well-defined salinity gradients to assess the split between palustrine emergent wetlands (non-tidal freshwater marshes) and estuarine emergent wetlands (tidal marshes). In reality, freshwater tidal marshes are intermediate to the palustrine emergent and estuarine emergent marshes, however, freshwater tidal zones in the Patuxent and Choptank Rivers were generally classified as palustrine emergent, indicating that classified time-series C-band SAR imagery and optical VIs are primarily detecting variability in vegetation structure and phenology rather than hydrologic variability. P. australis was mapped in all sites in Figure 11. P. australis tended to occur along wetland-upland edges and along freshwater-brackish transitions. The level-1 extent of $P$. australis agrees with previous publications in the Chesapeake Bay showing that P. australis was mostly present on the Chesapeake Bay's Eastern Shore and strongly associated with the presence of agriculture and moderate levels of disturbance [86]. The three emergent classes (estuarine emergent, palustrine emergent, and P. australis) were all classified with user's and producer's classification accuracies greater than $81 \%$ as shown in Table 2 . When these three emergent classes were aggregated into a single emergent wetland class, the user's accuracy increased to $89.69 \%$ and the producer's accuracy increased to $93.19 \%$.

Wetland Vegetation Classes at Wheeler Marshes (w), Jug Bay (jb), Hudson River (h)

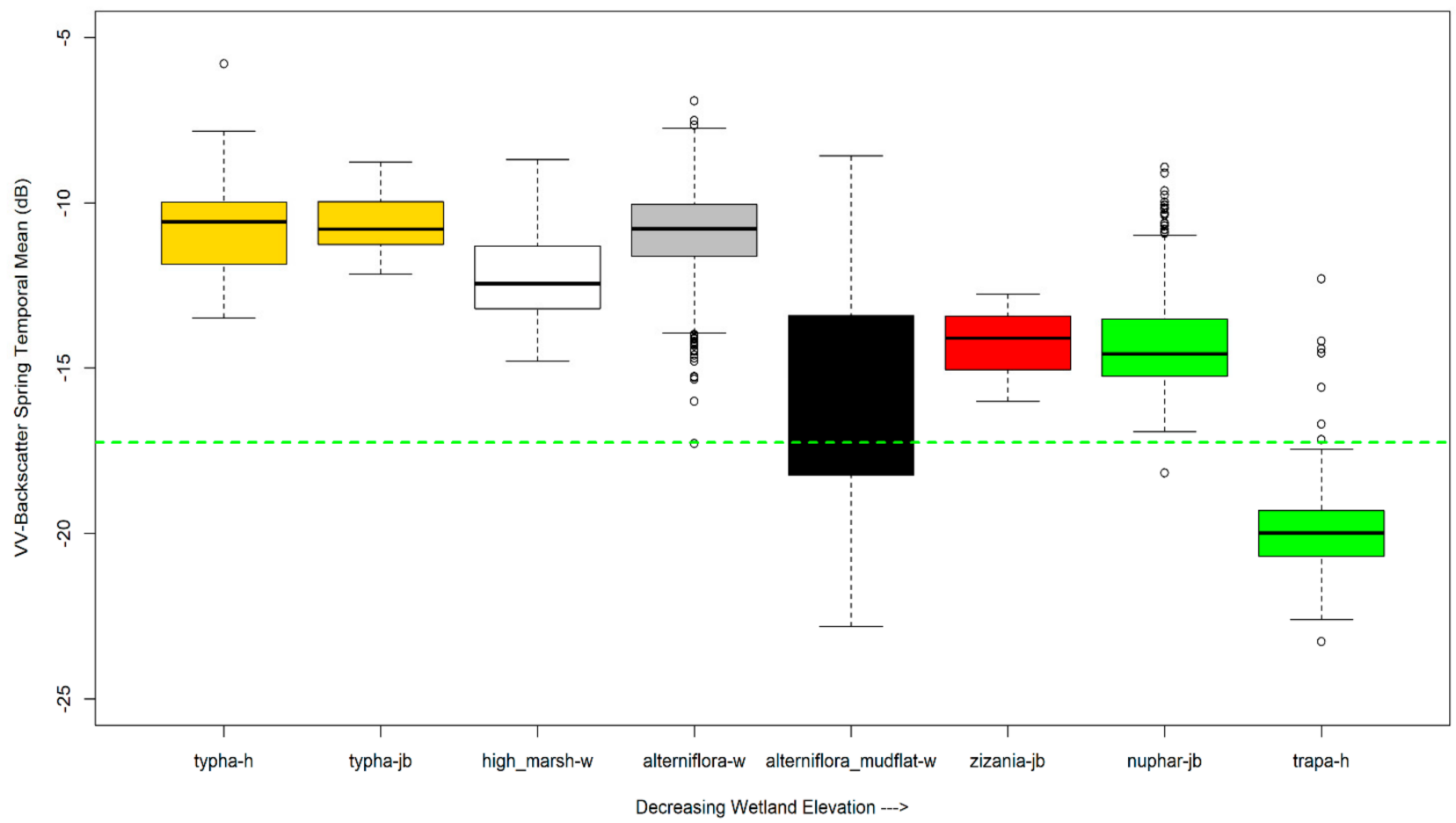

Figure 10. 2017 Sentinel-1 VV spring mean backscatter pixel values by wetland vegetation class at Wheeler Marshes (w), Jug Bay (jb), and Hudson River (h) sites. Naming convention, color schemes, and areas of extraction are the same as in Figure 9. Note with the VV spring layer, a threshold of $-17.25 \mathrm{~dB}$ separates T. natans from other non-persistent vegetation (horizontal dashed green line). 
Table 2. Mid-Atlantic level-1 random forest classification confusion matrix.

\begin{tabular}{|c|c|c|c|c|c|c|c|c|c|c|c|c|c|c|}
\hline \multicolumn{15}{|c|}{ Classification } \\
\hline \multirow{12}{*}{ Reference } & & water & urban & barren & grass & agriculture & shrub & $\begin{array}{c}\text { upland } \\
\text { forest }\end{array}$ & $\begin{array}{c}\text { woody } \\
\text { wetlands }\end{array}$ & $\begin{array}{l}\text { estuarine } \\
\text { emergent }\end{array}$ & $\begin{array}{l}\text { palustrine } \\
\text { emergent }\end{array}$ & $\begin{array}{c}\text { Phragmites } \\
\text { australis }\end{array}$ & Total & $\begin{array}{l}\text { Producer's } \\
\text { Accuracy \% } \\
\end{array}$ \\
\hline & water & 39,538 & 96 & 275 & 28 & 102 & 1 & 14 & 4 & 370 & 14 & 17 & 40,459 & 97.72 \\
\hline & barren & 561 & 3981 & 8849 & 839 & 3208 & 221 & 1587 & 155 & 1036 & 129 & 172 & 20,738 & 42.67 \\
\hline & grass & 18 & 5258 & 559 & 6667 & 10,207 & 1174 & 11,662 & 860 & 280 & 432 & 108 & 37,225 & 17.91 \\
\hline & agriculture & 23 & 3665 & 893 & 3092 & 47,904 & 827 & 6661 & 563 & 515 & 899 & 183 & 65,225 & 73.44 \\
\hline & shrub & 12 & 1991 & 206 & 2230 & 3359 & 3121 & 9460 & 1213 & 106 & 381 & 101 & 22,180 & 14.07 \\
\hline & forest & 13 & 1830 & 389 & 3148 & 5094 & 1327 & 94,643 & 5119 & 28 & 164 & 64 & 111,819 & 84.64 \\
\hline & estuarine & 249 & 213 & 333 & 76 & 252 & 9 & 15 & 42 & 19,043 & 312 & 1349 & 21,893 & 86.98 \\
\hline & palustrine & 49 & 167 & 72 & 175 & 1217 & 111 & 431 & 119 & 687 & 16,249 & 549 & 19,826 & 81.96 \\
\hline & Phragmites & 18 & 49 & 18 & 28 & 154 & 14 & 30 & 25 & 840 & 95 & 13,729 & 15,000 & 91.53 \\
\hline & Total & 40,537 & 39,410 & 13,327 & 20,016 & 77,635 & 7730 & 136,365 & 20,483 & 23,395 & 19,081 & 16,451 & - & - \\
\hline & $\begin{array}{c}\text { User's } \\
\text { Accuracy \% }\end{array}$ & 97.54 & 55.50 & 66.40 & 33.31 & 61.70 & 40.38 & 69.40 & 59.66 & 81.40 & 85.16 & 83.45 & - & $\frac{\frac{\text { Overall }}{\text { Accuracy } \%}}{68.49}$ \\
\hline
\end{tabular}

Table 3. Gulf Coast level-1 random forest classification confusion matrix.

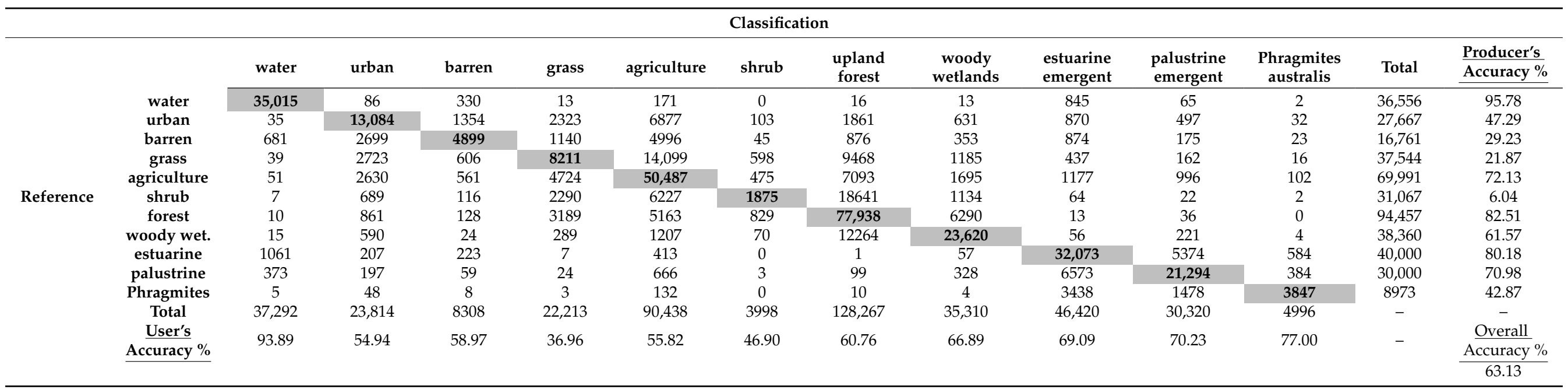




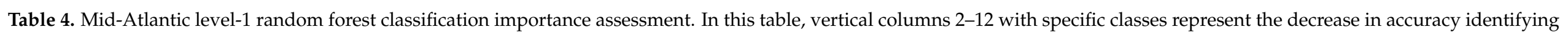

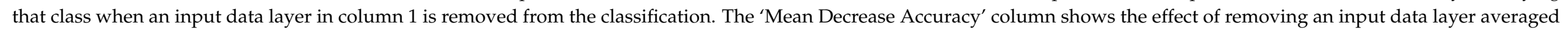
across classes.

\begin{tabular}{|c|c|c|c|c|c|c|c|c|c|c|c|c|}
\hline Layer/Class & Water & Urban & Barren & Grass & Agriculture & Shrub & $\begin{array}{l}\text { Upland } \\
\text { Forest }\end{array}$ & $\begin{array}{l}\text { Woody } \\
\text { Wetlands }\end{array}$ & $\begin{array}{l}\text { Estuarine } \\
\text { Emergent }\end{array}$ & $\begin{array}{l}\text { Palustrine } \\
\text { Emergent }\end{array}$ & $\begin{array}{c}\text { Phragmites } \\
\text { Australis }\end{array}$ & $\begin{array}{c}\text { Mean Decrease } \\
\text { Accuracy }\end{array}$ \\
\hline dem & 0.289 & 0.091 & 0.088 & 0.043 & 0.077 & 0.059 & 0.192 & 0.184 & 0.529 & 0.563 & 0.622 & 0.200 \\
\hline vv_mean & 0.295 & 0.115 & 0.067 & 0.019 & 0.088 & 0.010 & 0.148 & 0.125 & 0.146 & 0.318 & 0.307 & 0.140 \\
\hline vv_sd & 0.026 & 0.009 & 0.033 & 0.010 & 0.069 & 0.030 & 0.052 & 0.052 & 0.050 & 0.238 & 0.303 & 0.060 \\
\hline vv_spring & 0.052 & 0.052 & 0.049 & 0.011 & 0.057 & 0.022 & 0.109 & 0.078 & 0.125 & 0.244 & 0.266 & 0.085 \\
\hline vv_summer & 0.148 & 0.073 & 0.049 & 0.014 & 0.053 & 0.018 & 0.089 & 0.028 & 0.269 & 0.260 & 0.328 & 0.098 \\
\hline vv_fall & 0.513 & 0.062 & 0.027 & 0.012 & 0.036 & 0.020 & 0.081 & 0.041 & 0.070 & 0.186 & 0.247 & 0.110 \\
\hline
\end{tabular}

Table 5. Gulf Coast level-1 random forest classification importance assessment.

\begin{tabular}{|c|c|c|c|c|c|c|c|c|c|c|c|c|}
\hline Layer/Class & Water & Urban & Barren & Grass & Agriculture & Shrub & $\begin{array}{l}\text { Upland } \\
\text { Forest }\end{array}$ & $\begin{array}{c}\text { Woody } \\
\text { Wetlands }\end{array}$ & $\begin{array}{l}\text { Estuarine } \\
\text { Emergent }\end{array}$ & $\begin{array}{l}\text { Palustrine } \\
\text { Emergent }\end{array}$ & $\begin{array}{c}\text { Phragmites } \\
\text { Australis }\end{array}$ & $\begin{array}{c}\text { Mean Decrease } \\
\text { Accuracy }\end{array}$ \\
\hline dem & 0.108 & 0.089 & 0.060 & 0.079 & 0.106 & 0.066 & 0.185 & 0.169 & 0.413 & 0.400 & 0.283 & 0.173 \\
\hline vv_mean & 0.260 & 0.101 & 0.065 & 0.014 & 0.087 & -0.022 & 0.116 & 0.243 & 0.185 & 0.112 & 0.129 & 0.119 \\
\hline vh_mean & 0.282 & -0.002 & 0.094 & 0.036 & 0.166 & 0.021 & 0.164 & 0.211 & 0.126 & 0.045 & 0.189 & 0.132 \\
\hline vv_sd & 0.040 & 0.017 & 0.036 & 0.018 & 0.081 & 0.018 & 0.053 & 0.039 & 0.053 & 0.046 & 0.089 & 0.047 \\
\hline vv_spring & 0.140 & 0.070 & 0.027 & 0.015 & 0.038 & 0.004 & 0.066 & 0.057 & 0.108 & 0.097 & 0.106 & 0.064 \\
\hline vv_summer & 0.126 & 0.065 & 0.050 & 0.013 & 0.051 & 0.002 & 0.059 & 0.058 & 0.078 & 0.076 & 0.143 & 0.060 \\
\hline vv_fall & 0.077 & 0.049 & 0.039 & 0.011 & 0.031 & 0.002 & 0.050 & 0.025 & 0.076 & 0.030 & 0.128 & 0.042 \\
\hline
\end{tabular}



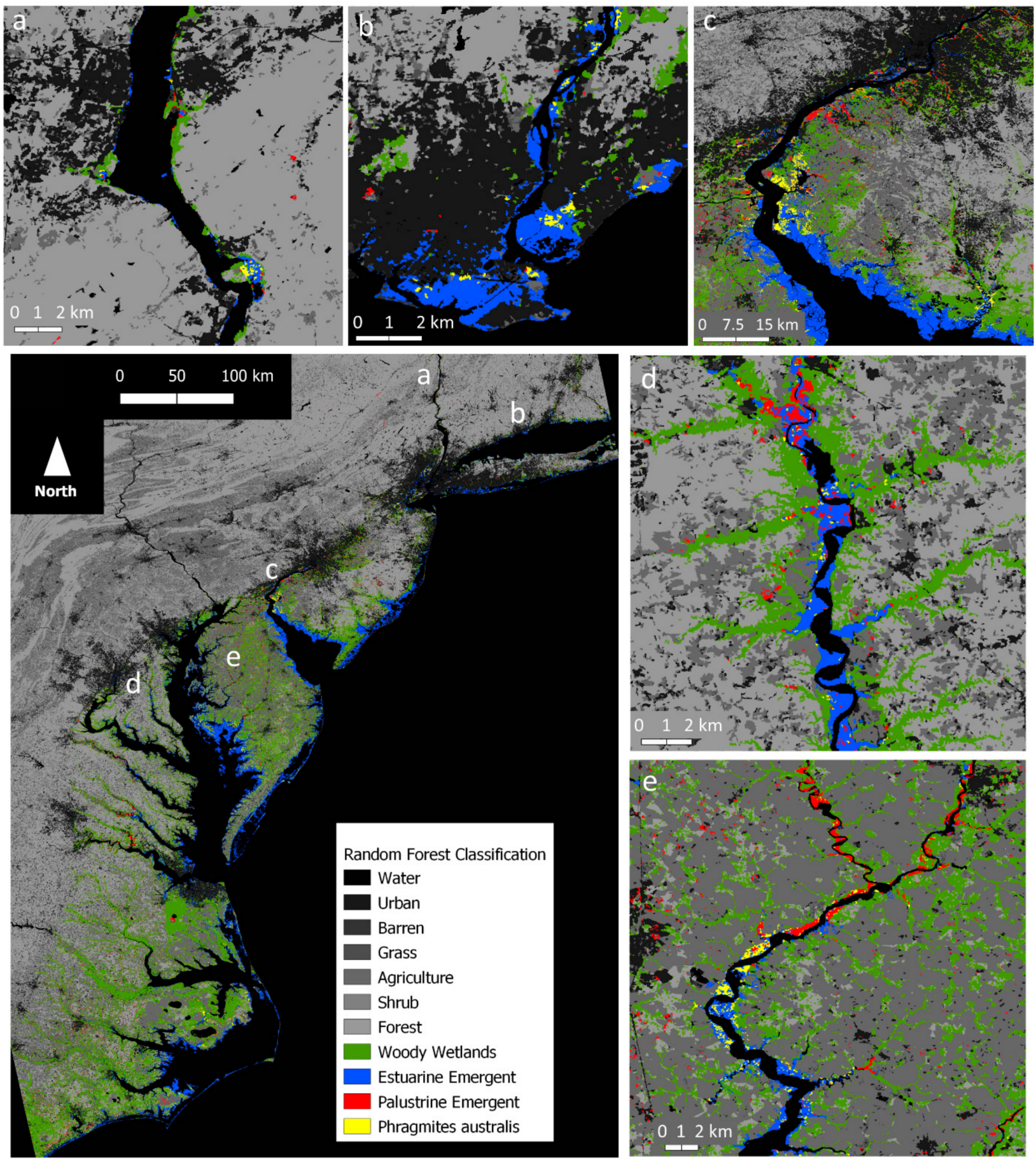

Figure 11. Mid-Atlantic level-1 classification using random forest. Panels a-e depict finer scale maps of the Hudson River wetlands (a), Housatonic River wetlands (b), Delaware River wetlands (c), Patuxent River wetlands (d), and Choptank River wetlands (e). The three separate emergent wetland classes are mapped with greater than $81 \%$ accuracy in all cases (see Table 2 confusion matrix). A clumped emergent wetland class (estuarine emergent, palustrine emergent, and P. australis) was mapped with a user's accuracy of $89.69 \%$ and producer's accuracy of $93.19 \%$.

The level-1 classification performance in the Gulf Coast region was evaluated in a similar manner. Four general study sites with strong salinity gradients were chosen as assessment sites. These sites included the Sabine River wetlands, Wax Lake Delta wetlands, Brenton Sound wetlands, and Bird's Foot Delta wetlands (Figure 12, panels a-d). The mapped wetland distributions in these sites indicate the presence of salinity 
gradients that are strongly influenced by the presence of major river systems. For instance, the Brenton Sound and Bird's Foot Delta classified wetlands indicate the presence of palustrine wetlands closest to the Mississippi River and major freshwater diversions, whereas estuarine emergent marshes dominate away from major freshwater discharges. $P$. australis was most common in the Bird's Foot Delta which largely agrees with descriptions of wetland vegetation in this area by the Audubon Society [87]. Overall classification accuracy of the three emergent classes for the Gulf Coast was much lower than MidAtlantic sites, at around 70\% (Table 3). However, the aggregation of these three emergent classes into a single emergent class yields accuracies higher than the Mid-Atlantic with a user's accuracy of $91.81 \%$ and producer's accuracy of $95.02 \%$.
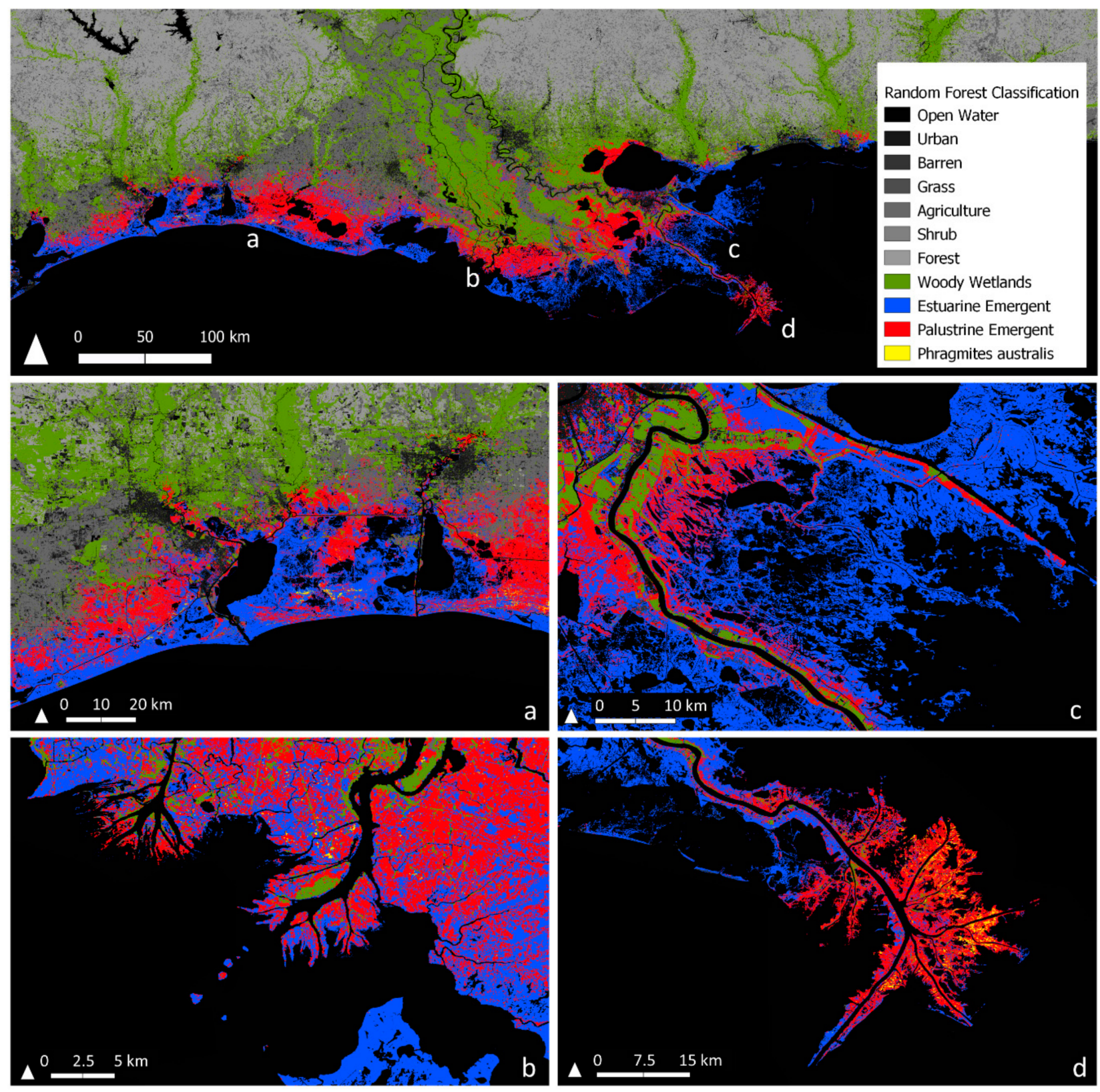

Figure 12. Gulf Coast level-1 classification using random forest. Panels a-d depict finer scale maps of the Sabine River wetlands (a), Wax Lake Delta wetlands (b), Brenton Sound wetlands (c), and Bird's Foot Delta wetlands (d). Classification accuracy of the three emergent classes is much lower than Mid-Atlantic sites at around 70\% (see Table 4 confusion matrix). However, the aggregation of these three emergent classes into a single emergent class yields accuracies higher than the Mid-Atlantic with a user's accuracy of $91.81 \%$ and producer's accuracy of $95.02 \%$. 
While the separation of estuarine emergent (tidal marshes), palustrine emergent (non-tidal freshwater marshes), and P. australis-dominated marshes were successful in the Mid-Atlantic region, the classification results still highlight some of the limitations of this approach. Notably, freshwater tidal wetlands are difficult to effectively map with a split between palustrine and estuarine emergent classes. This was indicated by the fact the tidal freshwater portions of the Choptank and Patuxent rivers were often classified as palustrine. These results are not unexpected as both tidal and non-tidal freshwater marshes often have similar vegetation communities. The level-2 classification results in the next section present potential solutions to determining the location of tidal freshwater wetlands within tidal marsh complexes.

For both the Mid-Atlantic and Gulf Coast sites, woody wetlands were identified with low accuracies of approximately $60 \%$. Woody wetlands were most commonly confused with upland forest in both regions (see Tables 2 and 3). This finding is not unexpected, given that C-band SAR responds most readily to emergent leaf structure and optical VIs provide assessments of upper canopy greenness, and thus neither are ideal data sources for identifying sub-canopy hydrology of woody vegetation. Although identification of such woody wetlands was not a primary objective of this study, the low performance should still be noted as a limitation.

Several important findings are of note in the post-classification accuracy of the level-1 classification results shown in Figures 11 and 12. First, the SRTM DEM was the most important layer for improving classification accuracy for all three emergent wetlands classes (Tables 4 and 5). These findings agree with those from Knight et al. (2013) [80]. Growing season NDVI was the second most important classification layer for both the Gulf Coast and Mid-Atlantic emergent classes. The third most important classification layer differed between the Gulf Coast and Mid-Atlantic with the annual mean VV backscatter being more important for the Gulf Coast emergent wetland classifications and annual mean VH backscatter being more important for the Mid-Atlantic (Table 4 vs. Table 5).

\subsection{Level-2 Classification Results}

The level-2 classification captured the non-persistent emergent vegetation and $T$. natans in the Mid-Atlantic (Figure 13). The Hudson River (panel-a) is the only system with significant T. natans identification. The Housatonic River/Wheeler Marsh classification (panel-b) shows no non-persistent vegetation, as expected for a brackish marsh system. The freshwater tidal systems of the Delaware River, Patuxent River, and Choptank Rivers (panels c-e) all show the presence of non-persistent emergent vegetation in the upper reaches and tributaries to the main river, all of which are less saline than the main river channel.

The level-2 classification results for the Gulf Coast similarly showed expected patterns for the distribution of non-persistent emergent vegetation. Note that, in contrast to the Mid-Atlantic classification effort, for the Gulf Coast there is one non-persistent class rather than a split between non-persistent emergent and non-persistent aquatic as shown in Figure 14. Non-persistent vegetation was largely associated with low salinity regions. In the Brenton Sound, the occurrence of non-persistent vegetation is minimal but tends to be associated with palustrine wetlands. The presence of non-persistent vegetation in the Wax Lake and Bird's Foot Delta wetlands is more expansive, but also tends to be associated with the presence of palustrine wetlands. In reality, these palustrine wetlands are likely tidal freshwater marshes. In the Bird's Foot Delta and Wax Lake Delta, classified non-persistent vegetation is indicative of the presence of Sagittaria spp. [85]. 

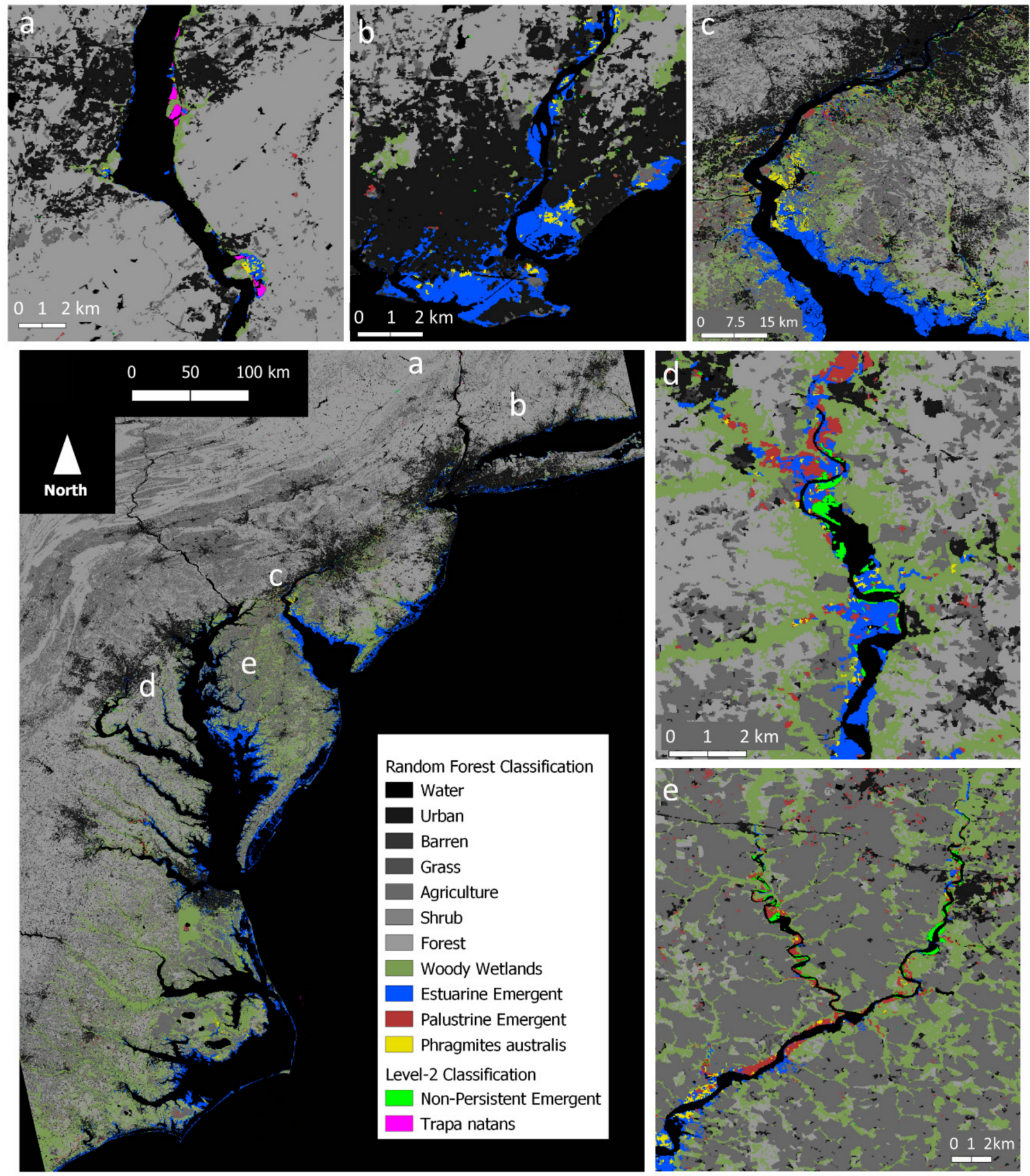

Figure 13. Maps of Mid-Atlantic level-2 classification, which use a decision tree classifier to modify the level-1 classification. Level-1 random forest classification wetland colors have been muted to highlight non-persistent emergent wetlands in bright green and T. natans in magenta. Panels (a-e) correspond to the Hudson River, Housatonic River/Wheeler Marsh, Delaware River Patuxent River, and Choptank River, respectively. Please note that the extents of panels (d,e) are zoomed relative to their extents in Figure 11. 

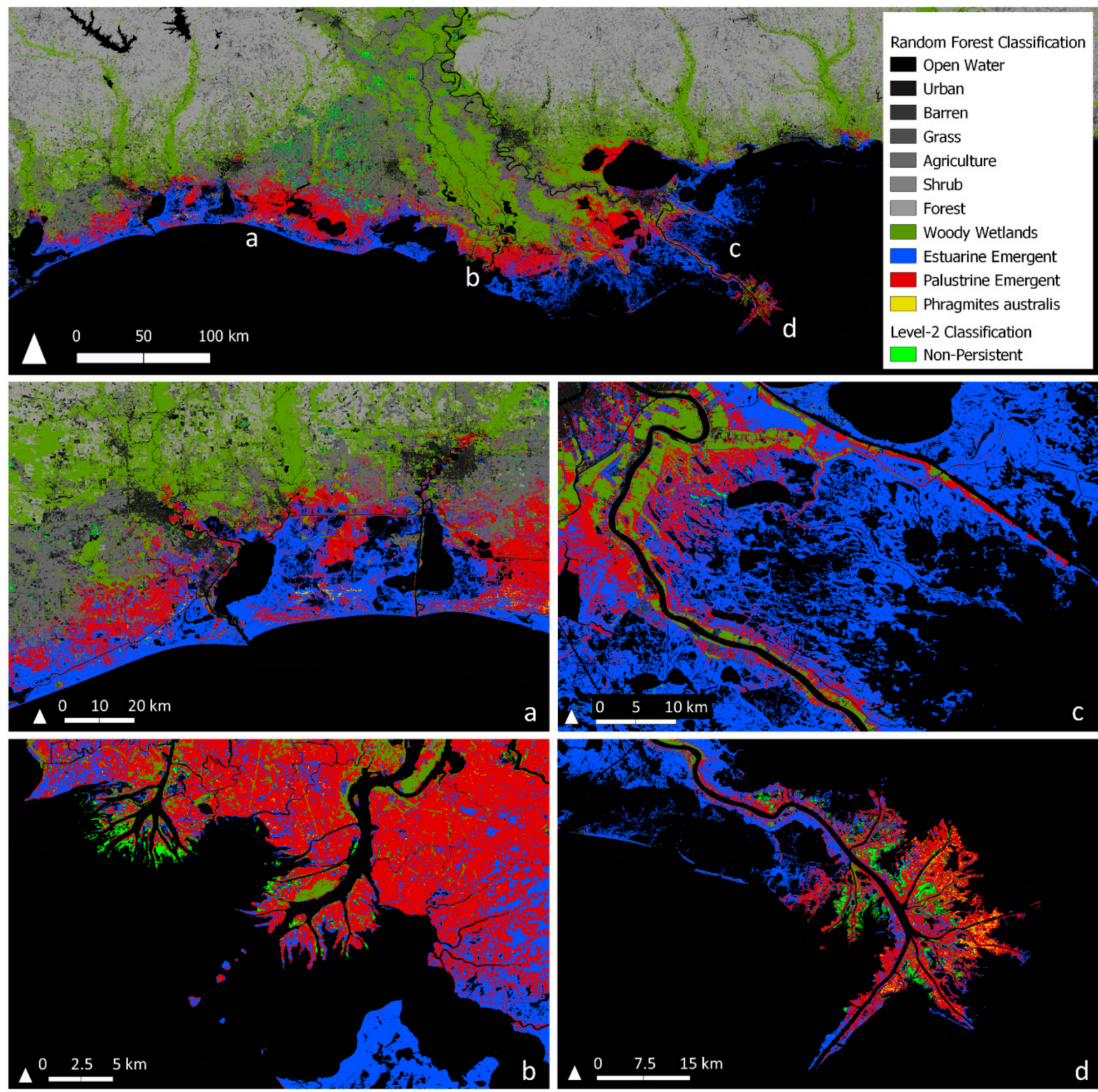

Figure 14. Maps of Gulf Coast level-2 classification, which use a decision tree classifier to modify the level-1 classification. Panels (a-d) correspond to the Sabine River, Wax Lake Delta (and surrounding wetlands), the Brenton Sound, and the Bird's Foot Delta, respectively. Note that level-1 emergent wetland colors have been muted to highlight locations of non-persistent vegetation in the level-2 classification.

\subsection{Level-2 Accuracy Assessment at Study Sites}

The level-2 accuracy assessment using the HRSAV, NAIP, and NWI shapefile datasets for the Hudson River, Choptank River, and Wax Lake Delta are shown in Figures 15-17, respectively. The accuracy assessment was also applied to the level-1 RF classification (prior to this classification being modified in the level-2 decision tree classification). The three shapefile datasets were used to extract pixels from the level-2 and level- 1 classifications, and accuracy was assessed via pixel occurrence within polygon boundaries. These results are shown in Table 6. 

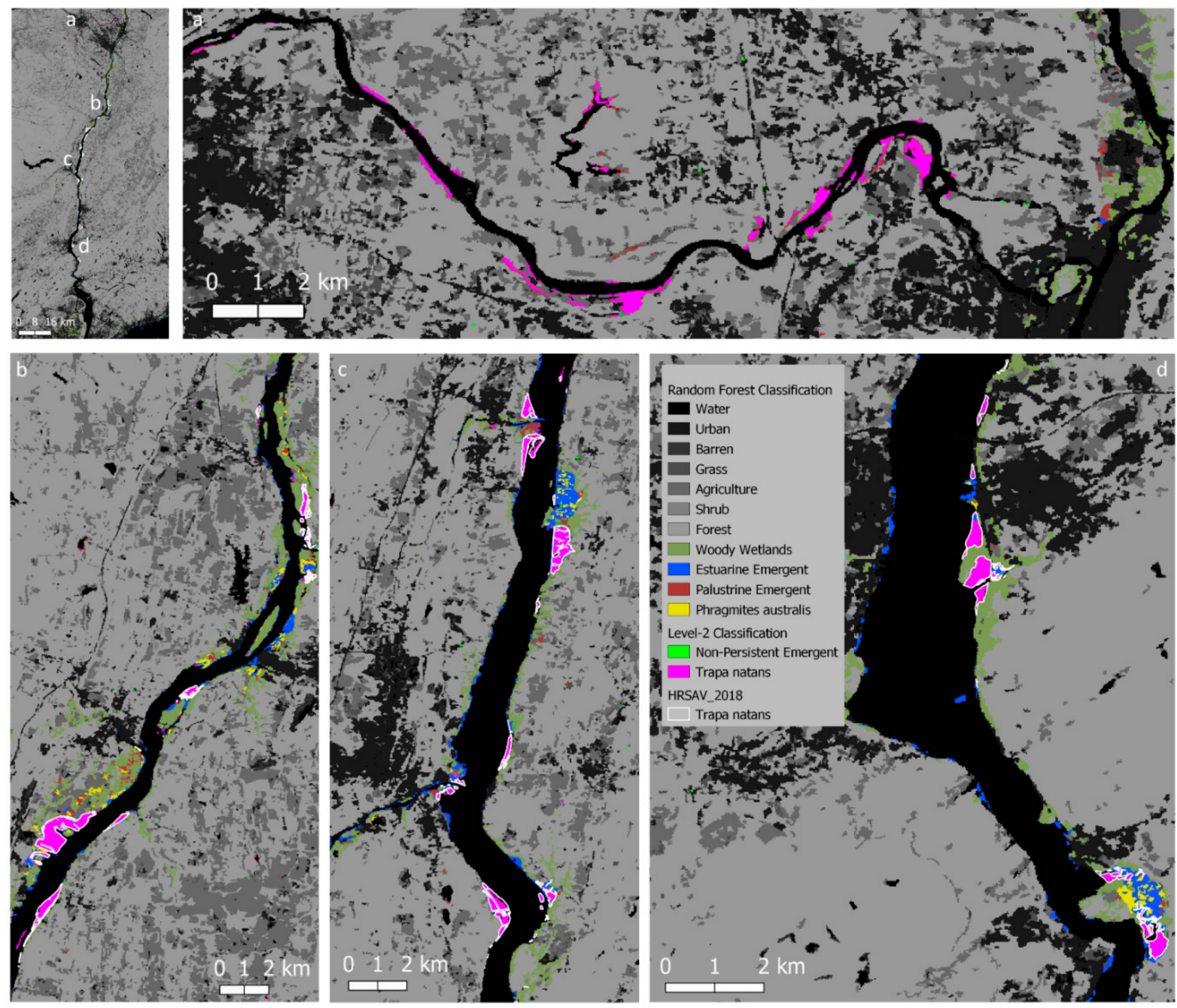

Figure 15. Comparison between Hudson River classified T. natans extents in level-2 classification and independent validation with 2018 HRSAV dataset. The small panned map in the upper left corner shows the Hudson River and locations of panels (a-d). Panel a showcases classified T. natans extent in the Mohawk River, a tributary to the Hudson River; note that the HRSAV dataset does not cover this site. T. natans occurrence accuracy was $96.47 \%$.

The level-2 classification for the Hudson River T. natans and Choptank River persistent emergent vs. non-emergent split was highly accurate. This is evidenced in Table 6 and Figures 15 and 16 demonstrating agreement between the independent evaluation datasets and high levels of accuracy ( $>93 \%)$. The Wax Lake Delta classification in comparison showed poor correspondence between the level-2 classification and all four NWI classes. This may have resulted from mixed vegetation occurring in NWI polygons. Further, Table 6 and Figure 17 demonstrate that many aquatic bed NWI classes were not detected as nonpersistent vegetation, but instead were classified as open water indicating that these aquatic beds may not have significant above water structure for a significant portion of a growing season. This would be expected if aquatic beds are dominated by rooted submerged vegetation (e.g., Ruppia maritima) vs. floating vegetation (e.g., Eichhornia crassipes). It should also be noted that a significant portion of level-1 pixels in NWI polygons was classified as agriculture, indicating potential confusion between wetlands and rice production. 


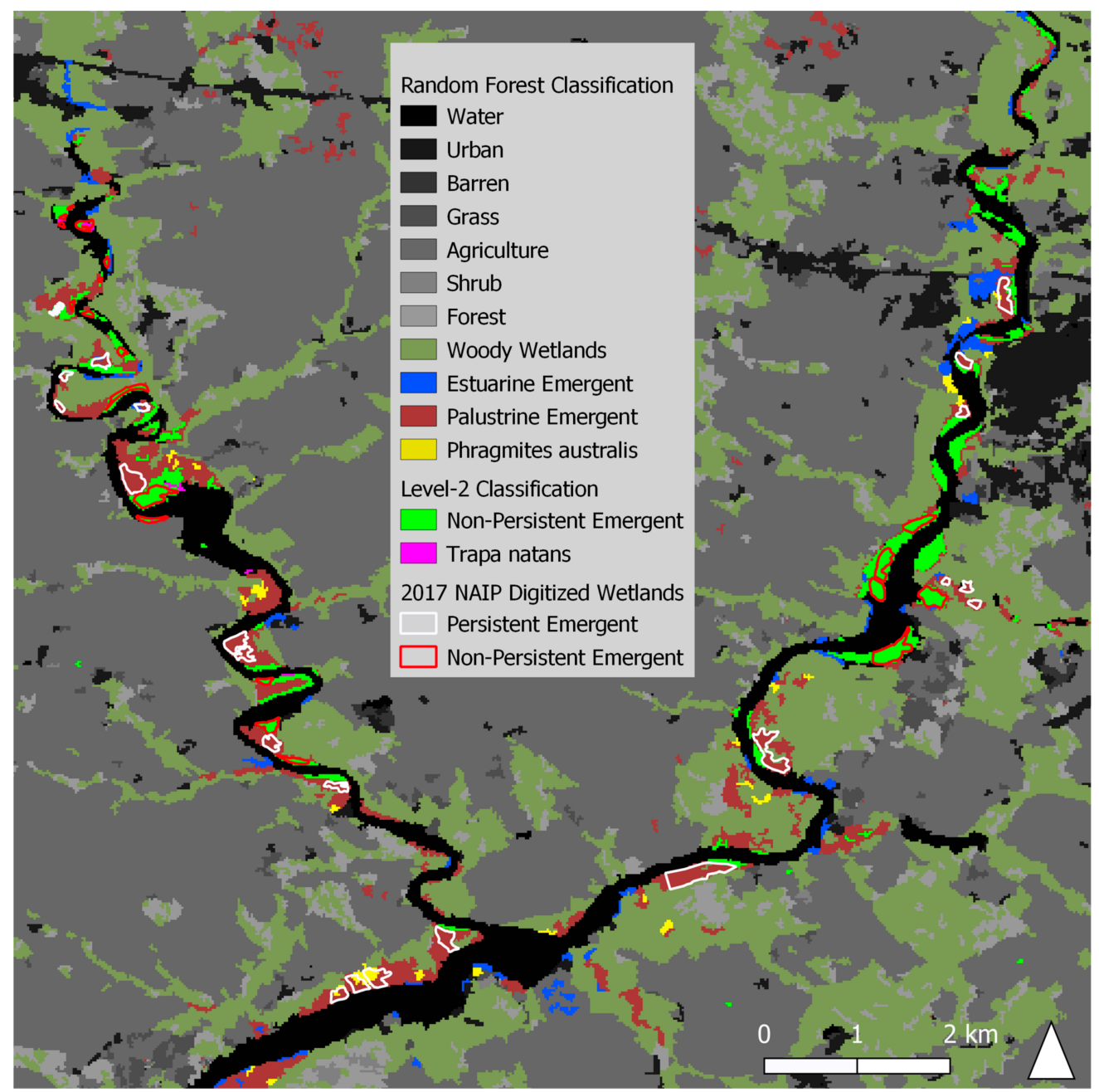

Figure 16. Comparison between Choptank River level-2 and level-1 classified wetland extents and independent validation with 2017 NAIP digitized wetland dataset. Identified non-persistent wetlands in the NAIP dataset were primarily Nuphar spp. Non-persistent emergent classification occurrence accuracy was $93.60 \%$. Persistent emergent classification occurrence accuracy was $95.79 \%$.
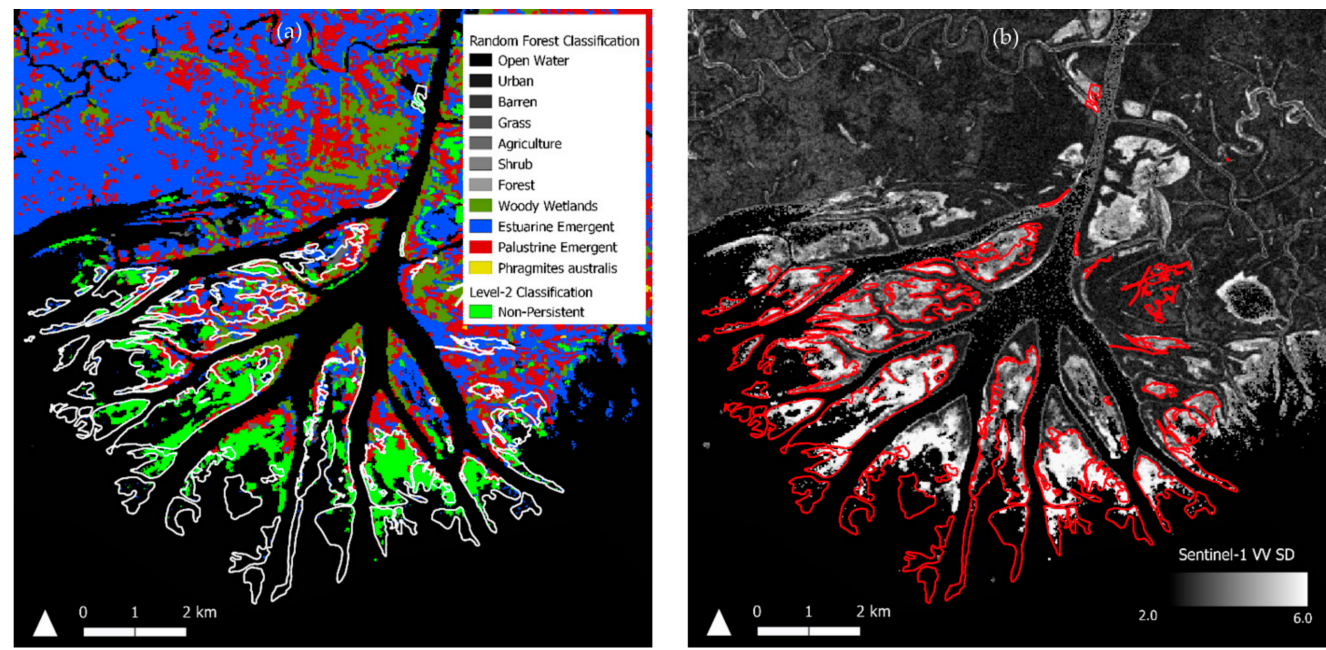

Figure 17. Left panel (a) depicts classified level-2 extents in 2017 NWI white polygons (white boundaries). Right panel (b) depicts the Sentinel-1 VV annual standard deviation layer with the same NWI polygons (red boundaries). 


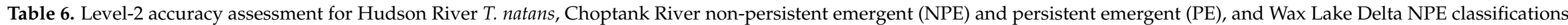
(four NWI classes). Occurrence accuracy percent serves as classification performance assessment.

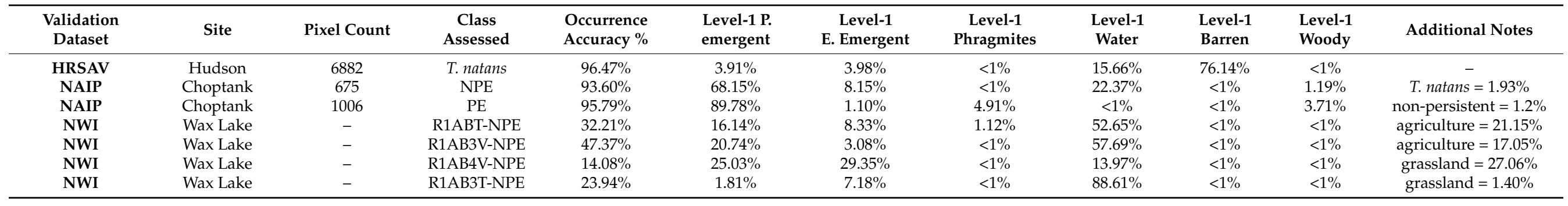




\section{Discussion}

The results of the level-1 classification demonstrate the utility of SAR-optical-DEM fusion in achieving relatively high emergent wetland classification accuracies. For both the Mid-Atlantic and Gulf Coast, emergent wetlands (i.e., marshes) (aggregation of estuarine emergent, palustrine emergent, and P. australis) were classified with user's and producer's accuracies greater than $89 \%$. The Gulf Coast combined emergent class user's accuracy was $91.81 \%$ and the producer's accuracy was $95.02 \%$. Application to the Mid-Atlantic coastline was slightly less accurate with user's accuracy of $89.69 \%$ and producer's accuracy of $93.19 \%$. Combined with the findings of open water being mapped with accuracies greater than $93.89 \%$ in all cases, the results demonstrate that this methodology presents an effective tool for monitoring annual emergent wetland loss through conversion to open water, with critical applications to both the Mid-Atlantic and Gulf Coast tidal wetlands [23,87,88]. The overall accuracies for the classification of emergent wetlands were comparable to NWI accuracy assessment studies, which generally find accuracies exceeding $90 \%$ at the NWI class level $[16,89,90]$. It is critical to note, however, that no previous studies have performed an extensive validation of the NWI for the mapping of estuarine emergent wetlands (i.e., tidal marshes).

The degree to which the level-1 classification methodology enabled us to distinguish between palustrine emergent, estuarine emergent, and P. australis dominated wetlands was variable. In the Mid-Atlantic, these classes were distinguished with better than $81 \%$ user's and producer's accuracy. Accuracies in the Gulf Coast were lower, with user's accuracies ranging from $69.07 \%$ to $77.00 \%$ and producer's accuracies ranging from $41.87 \%$ to $80.18 \%$ for the three emergent wetland classes. These results suggest that the level-1 classification methodology should be used only for general emergent wetlands mapping in the Gulf Coast at this time. It is quite likely that differences in vegetation phenology and hydrology explain some of the classification differences between the Mid-Atlantic and Gulf Coast, especially given that Sentinel-1 VV and VH polarization responses differ based on these factors [91].

The level-2 classification was developed from time-series analysis at Mid-Atlantic target sites, demonstrating that persistent and non-persistent vegetation had sufficiently different phenological signatures that were effectively detected by Sentinel-1A C-band SAR. We initially sought to determine whether vegetation phenological SAR signatures could be distinguished from hydrologic influence on SAR backscatter time-series in these tidal wetland systems. Figures 6 and 7 demonstrated that water level variability does have a pronounced impact on SAR backscatter, especially for low elevation wetland vegetation like S. alterniflora and N. lutea. However, when we temporally reduced Sentinel-1 image time-series to compute VV annual standard deviation (SD) layers and VV spring mean backscatter layers, these layers were demonstrated as being more responsive to vegetation structural phenological changes than hydrologic variability, such that thresholding approaches could be utilized to distinguish vegetation types. Thus, these Sentienl- 1 layers were selected as the basis for the level-2 classification, which proved to be quite accurate over Mid-Atlantic study sites. However, the broad applicability of this approach may be limited, given that decision tree thresholds were obtained only from select study sites and further assessment of accuracy across different regions is needed. For our study sites, the accuracy of the level-2 classification results was greatest for the detection of T. natans in the Hudson River (>96\%). Other sites where T. natans has not been observed (Jug Bay and Wheeler Marsh) did not show incorrect T. natans identifications, even with Jug Bay being dominated by large stands of non-persistent $N$. lutea, which shares similar phenology. Initially, we suspected that $T$. natans and N. lutea may be distinguished based on biomassbased backscatter differences during the growing season. However, the assessment of Sentinel-1 VV backscatter time-series showed that during peak growth in July and August, both species had nearly identical peak backscatter values $(-6 \mathrm{~dB})$. The similarities in peak growth backscatter points to both species exhibiting strong surface scattering compared 
to a canopy scattering response that would exhibit greater backscatter differences based on biomass.

The brackish wetlands of Wheeler Marsh and the lower Housatonic River largely lacked any classified non-persistent vegetation, indicating an accurate level-2 classification (Figure 13). Level-2 classification accuracy for the Choptank River site was also high with non-persistent emergent wetlands and persistent emergent wetlands both being classified with greater than 93\% accuracy. The level-2 classification accuracy for non-persistent vegetation in the Wax Lake Delta was only $47.3 \%$, which was far less accurate than the MidAtlantic sites. However, it is important to note that the Wax Lake Delta NWI validation dataset, in this case, may not be as accurate as the Choptank NAIP-based validation dataset that was carefully digitized with a singular objective of separating persistent and non-persistent vegetation types in Mid-Atlantic systems, and the Hudson River HRSAV dataset that identified a single target species. Several studies have noted mixed stands of specific vegetation in the Wax Lake Delta wetlands $[85,92,93]$, which the NWI may not classify accurately.

The combined results of the level-2 and level-1 classifications yielded some important findings with respect to differences between these classifications. In the level-2 accuracy assessment for the Hudson River (Figure 16), the overwhelming majority of identified non-persistent vegetation was T. natans. Level-2 classified T. natans co-occurred with the level-1 classification barren class, which includes mudflats, at 76.14\%. T. natans also co-occurred in $15.66 \%$ of open water classified pixels, in $3.98 \%$ of classified estuarine emergent wetlands, and in 3.91\% of classified palustrine emergent wetlands from the level1 classification. The fact that T. natans was most common in the barren class may be a level-1 classification inaccuracy due to confusion of shallow open waters with mudflats. The level1 classification results may also be the result of mudflats being intermittently exposed depending on season and hydrologic stage. Field observations indicated that T. natans tended to occur in very shallow waters. Given that this species is floating aquatic vegetation, there is also potential for clustering in very shallow waters and/or mudflats after riverine transport. Comparatively, the Choptank River level-2 non-persistent emergent class did not co-occur with the level-1 barren class $(<1 \%)$, which may be due to non-persistent emergents having a longer period of vegetated cover over the mudflats they grow in compared to T. natans, which is more ephemeral in nature (Figure 7 vs. Figure 8). Instead, non-persistent emergents were generally classified as palustrine emergent wetlands at $68.15 \%$ and open water at $22.37 \%$ in the level- 1 classification. These results indicate that vegetation phenology had a non-trivial impact on the level-1 classification and that the level-2 classification provided additional utility in the interpretation of level- 1 results. The level-1 and level-2 classification findings illustrated how machine learning and explicitly defined decision tree approaches can complement and corroborate one another.

\section{Conclusions}

We produced updated coastal wetlands and deepwater maps for the Mid-Atlantic and Gulf Coast United States for 2017. Application of this approach to the Mid-Atlantic coast resulted in relatively high accuracies (>80\%) for the separation of estuarine marshes, palustrine marshes, and Phragmites australis-dominated marshes; yet the approach had lower accuracy in the Gulf Coast. For both the Mid-Atlantic and Gulf Coast regions, emergent wetlands and open water were mapped with greater than $90 \%$ accuracy, meaning this methodology has clear applications for monitoring of marsh loss, especially considering that it can be updated annually.

For the purpose of developing a global tidal marsh inventory, Sentinel-1 SAR, Landsat 8 optical, and SRTM DEM all provide coverage for such a product. However, this product may need to be tailored for specific regions based on a priori understanding of marsh structure, phenology, and hydrology, which was indicated by differences in classification accuracy between the Mid-Atlantic and Gulf Coast regions. Additionally, in terms of achieving a global tidal marsh product, training data availability may be a substantial issue, 
especially for training data selection for non-tidal wetland classes. Although the Mcowen tidal marsh inventory presents a potential training dataset for global tidal marsh mapping efforts, it is unclear if inventories akin to the Mcowen tidal marsh inventory exist for other wetlands classes and cover classes that possess similarities, and thus potential confusion with wetlands and deepwaters, such as rice paddies and aquaculture. It is critical to have several non-wetlands classes included in wetland classification schema for identifying non-wetlands regions and for confusion testing. Global products such as the MODIS Land Cover product, GlobeLand30, or Copernicus Global Land Cover product may be useful as training data in this regard for identifying emergent wetlands and woody wetlands as well as non-wetland classes. These emergent wetland classes could be referenced with the Mcowen tidal marsh inventory to split tidal emergent marshes from palustrine emergent marshes, forming a global training dataset. This remains a potential area of future research.

Overall, the level-1 classification yielded accurate results that point to its applicability to global tidal marsh mapping. However, the novelty of this study lies in the level-2 classification, which represents the first time C-band SAR was used to effectively map and separate persistent emergent, non-persistent emergent, and floating aquatic vegetation in coastal wetlands-deepwater systems. Prior studies enlisting optically based remote sensing techniques have been used to map similar vegetation classes [44,45]. Here, we demonstrated that SAR provides the ability to separate above- and below-water aquatic vegetation more effectively than optically based approaches, while optical approaches have a clear advantage in assessing the presence or absence of below-surface aquatic vegetation. The level-2 classification results demonstrate that time-series approaches with Sentinel-1 C-band SAR imagery present numerous opportunities for characterization and monitoring of emergent wetlands and deepwaters. Further, our approaches can be modified for use in different regions where emergent and floating aquatic vegetation have different phenologies, as C-band SAR was demonstrably sensitive to phenological change for both floating and emergent vegetation, even more so than extreme water level changes (Figure 8).

With the anticipated launch of the NASA-ISRO Synthetic Aperture Radar (NISAR) satellite operating at the longer L-band wavelength (at times operating at S-band as well), the fusion of vegetation response from Sentinel-1 C-band SAR with sub-canopy surface water characterization from NISAR L-band SAR presents even further opportunities in wetland and deepwater monitoring and characterization. The inclusion of L-band imagery in classifications will likely greatly increase the classification accuracy of woody wetlands and provide better separation between woody and emergent wetlands [70,71]. The launch of NISAR, currently planned for 2022, will demarcate a time in history where optical, C-band SAR, and L-band SAR satellites will acquire Earth imagery at similar spatial resolutions, revisit times, and with similar near-global coverages. This presents a great opportunity for the future of wetlands monitoring and characterization.

Author Contributions: Conceptualization, B.T.L., M.A.T., K.C.M.; methodology, B.T.L., K.C.M., M.A.T.; software, B.T.L.; validation, B.T.L.; formal analysis, B.T.L.; investigation, B.T.L., M.A.T., K.C.M.; resources, M.A.T., K.C.M., B.T.L.; data curation, B.T.L.; writing-original draft preparation, B.T.L.; writing—review and editing, M.A.T., K.C.M., B.T.L.; visualization, B.T.L.; supervision, M.A.T., K.C.M.; project administration, M.A.T., K.C.M.; funding acquisition, M.A.T., K.C.M., B.T.L. All authors have read and agreed to the published version of the manuscript.

Funding: This research was funded by the NASA Carbon Cycle Science Program (grant number NNX14AP06G), NASA Interdisciplinary Science Program (grant number 80NSSC17K0258), and the NASA Earth and Space Science Fellowship (NESSF) Program (grant number 80NSSC17K0365). Portions of this work were carried out at the Jet Propulsion Laboratory, California Institute of Technology, under contract to the National Aeronautics and Space Administration.

Data Availability Statement: All satellite imagery, aerial photography, and shapefile datasets used in this study are open access. Classification products are available upon request by contacting the authors. 
Conflicts of Interest: The authors declare no conflict of interest.

Additional Support: This research was conducted in part under the framework of the ALOS Kyoto and Carbon Initiative. This study and manuscript benefited greatly from suggestions and reviews by Dorothy Peteet of Lamont-Doherty Earth Observatory and Andrew Reinmann of the CUNY Advanced Science Research Center.

\section{References}

1. McLeod, E.; Chmura, G.L.; Bouillon, S.; Salm, R.; Bjork, M.; Duarte, C.M.; Lovelock, C.E.; Schlesinger, W.H.; Silliman, B.R. A blueprint for blue carbon: Toward an improved understanding of the role of vegetated coastal habitats in sequestering $\mathrm{CO}_{2}$. Front. Ecol. Environ. 2011, 9, 552-560. [CrossRef]

2. Howard, J.; Sutton-Grier, A.; Herr, D.; Kleypas, J.; Landis, E.; Mcleod, E.; Pidgeon, E.; Simpson, S. Clarifying the role of coastal and marine systems in climate mitigation. Front. Ecol. Environ. 2017. [CrossRef]

3. Hinson, A.L.; Feagin, R.A.; Eriksson, M.; Najjar, R.G.; Herrmann, M.; Bianchi, T.S.; Kemp, M.; Hutchings, J.A.; Crooks, S.; Boutton, T. The spatial distribution of soil organic carbon in tidal wetland soils of the continental United States. Glob. Chang. Biol. 2017, 23, 5468-5480. [CrossRef] [PubMed]

4. Thomas, N.; Lucas, R.; Bunting, P.; Hardy, A.; Rosenqvist, A.; Simard, M. Distribution and drivers of global mangrove forest change, 1996-2010. PLoS ONE 2017, 12, 1-14. [CrossRef]

5. Bunting, P.; Rosenqvist, A.; Lucas, R.M.; Rebelo, L.M.; Hilarides, L.; Thomas, N.; Hardy, A.; Itoh, T.; Shimada, M.; Finlayson, C.M. The global mangrove watch-A new 2010 global baseline of mangrove extent. Remote Sens. 2018, 10, 1669. [CrossRef]

6. Pendleton, L.; Donato, D.C.; Murray, B.C.; Crooks, S.; Jenkins, W.A.; Sifleet, S.; Craft, C.; Fourqurean, J.W.; Kauffman, J.B.; Marb, N. Estimating Global "Blue Carbon" Emissions from Conversion and Degradation of Vegetated Coastal Ecosystems. PLoS ONE 2012, 7, e43542. [CrossRef]

7. Mcowen, C.; Weatherdon, L.; Bochove, J.-W.; Sullivan, E.; Blyth, S.; Zockler, C.; Stanwell-Smith, D.; Kingston, N.; Martin, C.; Spalding, M.; et al. A global map of saltmarshes. Biodivers. Data J. 2017, 5, e11764. [CrossRef]

8. Rooth, J.E.; Stevenson, J.C. Sediment deposition patterns in P. australis communities: Implications for coastal areas threatened by rising sea-level. Wetl. Ecol. Manag. 2000, 8, 173-183. [CrossRef]

9. Leonard, L.A.; Croft, A.L. The effect of standing biomass on flow velocity and turbulence in S. alterniflora canopies. Estuar. Coast. Shelf Sci. 2006, 69, 325-336. [CrossRef]

10. Feagin, R.A.; Forbrich, I.; Huff, T.P.; Barr, J.G.; Ruiz-Plancarte, J.; Fuentes, J.D.; Najjar, R.G.; Vargas, R.; Vázquez-Lule, A.; Windham-Myers, L.; et al. Tidal Wetland Gross Primary Production Across the Continental United States, 2000-2019. Glob. Biogeochem. Cycles 2020, 34, 1-25. [CrossRef]

11. Odum, W.E. Comparative ecology of tidal freshwater and salt marshes. Annu. Rev. Ecol. Syst. 1988, 19, 147-176. [CrossRef]

12. Elmore, A.H. Remote Sensing of Tidal Freshwater Marsh Elevation, Channels, and Vegetation Structure. Masters Thesis, University of Maryland, Supervised by Professor Katharina Engelhardt, College Park, MA, USA, 2008.

13. Bertness, M.D.; Ewanchuk, P.J.; Silliman, B.R. Anthropogenic modification of New England salt marsh landscapes. Proc. Natl. Acad. Sci. USA 2002, 99, 1395-1398. [CrossRef]

14. Cowardin, L.M.; Carter, V.; Golet, F.C.; LaRoe, E.T. Classification of Wetlands and Deepwater Habitats of the United States; U.S. Fish and Wildlife Service, Office of Biological Services: Washington, DC, USA, 1979.

15. Federal Geographic Data Committee. Classification of Wetlands and Deepwater Habitats of the United States. 2013. Available online: https:/ / www.fws.gov/wetlands/Documents / Classification-of-Wetlands-and-Deepwater-Habitats-of-the-United-States2013.pdf (accessed on 1 July 2019).

16. Kudray, G.M.; Gale, M.R. Evaluation of National Wetland Inventory maps in a heavily forested region in the upper Great Lakes. Wetlands 2000, 20, 581-587. [CrossRef]

17. Homer, B.C.; Dewitz, J.; Yang, L.; Jin, S.; Danielson, P.; Coulston, J.; Herold, N.; Wickham, J.; Megown, K. Completion of the 2011 National Land Cover Database for the Conterminous United States-Representing a Decade of Land Cover Change Information. Photogramm. Eng. Remote Sens. 2015, 81, 345-354.

18. Yang, L.; Jin, S.; Danielson, P.; Homer, C.; Gass, L.; Bender, S.M.; Case, A.; Costello, C.; Dewitz, J.; Fry, J.; et al. A new generation of the United States National Land Cover Database: Requirements, research priorities, design, and implementation strategies. ISPRS J. Photogramm. Remote Sens. 2018, 146, 108-123. [CrossRef]

19. Tiner, R.W. NWI Maps: What They Tell Us. Natl. Wetl. Newsl. 1997, 19, 7-12.

20. National Oceanic and Atmospheric Administration, Office for Coastal Management. 2016 C-CAP Regional Land Cover Coastal Change Analysis Program (C-CAP) Regional Land Cover. Charleston, SC: NOAA Office for Coastal Management. Available online: www.coast.noaa.gov/htdata/raster1/landcover/bulkdownload/30m_lc/ (accessed on 20 April 2021).

21. Campbell, A.; Wang, Y.; Christiano, M.; Stevens, S. Salt Marsh Monitoring in Jamaica Bay, New York from 2003 to 2013 : A decade of change from restoration to hurricane sandy. Remote Sens. 2017, 9, 131. [CrossRef]

22. Howes, N.C.; FitzGerald, D.M.; Hughes, Z.J.; Georgiou, I.Y.; Kulp, M.A.; Miner, M.D.; Smith, J.M.; Barras, J.A. Hurricane-induced failure of low salinity wetlands. Proc. Natl. Acad. Sci. USA 2010, 107, 14014-14019. [CrossRef]

23. Turner, R.E.; Layne, M.; Mo, Y.; Swenson, E.M. Net land gain or loss for two Mississippi River diversions: Caernarvon and Davis Pond. Restor. Ecol. 2019, 27, 1231-1240. [CrossRef] 
24. Beckett, L.H.; Baldwin, A.H.; Kearney, M.S. Tidal marshes across a Chesapeake Bay subestuary are not keeping up with sea-level rise. PLoS ONE 2016, 11, 1-12. [CrossRef]

25. Byrd, K.B.; Ballanti, L.; Thomas, N.; Nguyen, D.; Holmquist, J.R.; Simard, M.; Windham-Myers, L. A remote sensing-based model of tidal marsh aboveground carbon stocks for the conterminous United States. ISPRS J. Photogramm. Remote Sens. 2018, 139, 255-271.

26. Holmquist, J.R.; Windham-Myers, L.; Bernal, B.; Byrd, K.B.; Crooks, S.; Gonneea, M.E.; Herold, N.; Knox, S.H.; Kroeger, K.D.; McCombs, J.; et al. Uncertainty in United States coastal wetland greenhouse gas inventorying. Environ. Res. Lett. 2018, 13, 115005. [CrossRef]

27. Herbert, E.R.; Schubauer-Berigan, J.; Craft, C.B.; Affairs, E.; Agency, E.P.; Risk, N. Differential effects of chronic and acute simulated seawater intrusion on tidal freshwater marsh carbon cycling. Biogeochemistry 2018, 138, 137-154. [CrossRef]

28. Ross, P.; Adam, P. Climate Change and Intertidal Wetlands. Biology 2013, 2, 445-480. [CrossRef]

29. Tobias, C.; Neubauer, S. Chapter 16-Salt Marsh Biogeochemistry-An Overview. Coastal Wetlands 2009, 76, 539-596.

30. Bartlett, D.S.; Klemas, V. In situ spectral reflectance studies of tidal wetland grasses. Photogramm. Eng. Remote Sens. 1981, 47, 1695-1703.

31. Kearney, M.S.; Rogers, A.S.; Townshend, J.R.G.; Rizzo, E.; Stutzer, D.; Stevenson, J.C.; Sundborg, K. Landsat imagery shows decline of coastal marshes in Chesapeake and Delaware Bays. Eos. Trans. Am. Geophys. Union 2002, 83, 173. [CrossRef]

32. Kulawardhana, R.W.; Thenkabail, P.S.; Vithanage, J.; Biradar, C.; Islam, M.A.A.; Gunasinghe, S.; Alankara, R. Evaluation of the wetland mapping methods using Landsat ETM+ and SRTM data. J. Spat. Hydrol. 2007, 7, 62-96.

33. Ozesmi, S.L.; Bauer, M.E. Satellite remote sensing of wetlands. Wetl. Ecol. Manag. 2002, 10, 381-402. [CrossRef]

34. Frohn, R.C.; Reif, M.; Lane, C.; Autrey, B. Satellite remote sensing of isolated wetlands using object-oriented classification of Landsat-7 data. Wetlands 2009, 29, 931-941. [CrossRef]

35. Couvillion, B.R.; Barras, J.A.A.; Steyer, G.D.D.; Sleavin, W.; Fischer, M.; Beck, H.; Trahan, N.; Griffin, B.; Heckman, D.; Catherine, S.; et al. Land Area Change in Coastal Louisiana from 1932 to 2010. U.S. Geol. Surv. Sci. Investig. 2011, 3164, 12.

36. Gilmore, M.S.; Wilson, E.H.; Barrett, N.; Civco, D.L.; Prisloe, S.; Hurd, J.D.; Chadwick, C. Integrating multi-temporal spectral and structural information to map wetland vegetation in a lower Connecticut River tidal marsh. Remote Sens. Environ. 2008, 112, 4048-4060. [CrossRef]

37. Hurd, J.D.; Civco, D.L.; Gilmore, M.S.; Prisloe, S.; Wilson, E.H. Coastal marsh characterization using satellite remote sensing and in situ radiometry data: Preliminary results. In Proceedings of the American Society of Photogrammetry and Remote Sensing 2005 Annual Conference, Baltimore, MD, USA, 7-11 March 2005.

38. Klemas, V. Using Remote Sensing to Select and Monitor Wetland Restoration Sites: An Overview. J. Coast. Res. 2013, 289, 958-970. [CrossRef]

39. Langley, J.A.; Megonigal, J.P. Field-based radiometry to estimate tidal marsh plant growth in response to elevated $\mathrm{CO}_{2}$ and nitrogen addition. Wetlands 2012, 32, 571-578. [CrossRef]

40. Lopes, C.L.; Mendes, R.; Caçador, I.; Dias, J.M. Assessing salt marsh extent and condition changes with 35 years of Landsat imagery: Tagus Estuary case study. Remote Sens. Environ. 2020, 247, 111939. [CrossRef]

41. Van Beijma, S.; Comber, A.; Lamb, A. Random forest classification of salt marsh vegetation habitats using quad-polarimetric airborne SAR, elevation, and optical RS data. Remote Sens. Environ. 2014, 149, 118-129. [CrossRef]

42. Lamb, B.T.; Tzortziou, M.A.; McDonald, K.C. Evaluation of Approaches for Mapping Tidal Wetlands of the Chesapeake and Delaware Bays. Remote Sens. 2019, 11, 2366. [CrossRef]

43. Mahdianpari, M.; Salehi, B.; Mohammadimanesh, F.; Homayouni, S.; Gill, E. The first wetland inventory map of newfoundland at a spatial resolution of $10 \mathrm{~m}$ using sentinel-1 and sentinel-2 data on the Google Earth Engine cloud computing platform. Remote Sens. 2019, 11, 43. [CrossRef]

44. Villa, P.; Bresciani, M.; Bolpagni, R.; Pinardi, M.; Giardino, C. A rule-based approach for mapping macrophyte communities using multi-temporal aquatic vegetation indices. Remote Sens. Environ. 2015, 171, 218-233. [CrossRef]

45. Villa, P.; Pinardi, M.; Toth, V.R.; Hunter, P.D.; Bolpagni, R.; Bresciani, M. Remote sensing of macrophyte traits: Implications for the management of shallow lakes. J. Limnol. 2017, 76, 1629. [CrossRef]

46. Jones, J.W. Improved automated detection of subpixel-scale inundation-revised Dynamic Surface Water Extent (DSWE) partial surface water tests. Remote Sens. 2019, 11, 374. [CrossRef]

47. O'Connell, J.L.; Mishra, D.R.; Cotten, D.L.; Wang, L.; Alber, M. The Tidal Marsh Inundation Index (TMII): An inundation filter to flag flooded pixels and improve MODIS tidal marsh vegetation time-series analysis. Remote Sens. Environ. 2017, 201, 34-46. [CrossRef]

48. Atwood, D.; Battaglia, M.; Bourgeau-Chavez, L.; Ahern, F.; Murnaghan, K.; Brisco, B. Exploring Polarimetric Phase of Microwave Backscatter from Typha Wetlands. Can. J. Remote Sens. 2020, 46, 49-66. [CrossRef]

49. Brisco, B.; Kapfer, M.; Hirose, T.; Tedford, B.; Liu, J. Evaluation of C-band polarization diversity and polarimetry for wetland mapping. Can. J. Remote Sens. 2011, 37, 82-92. [CrossRef]

50. Brisco, B.; Ahern, F.; Murnaghan, K.; White, L.; Canisus, F.; Lancaster, P. Seasonal change in wetland coherence as an aid to wetland monitoring. Remote Sens. 2017, 9, 158. [CrossRef]

51. Kasischke, E.S.; Bourgeau-Chavez, L.L. Monitoring south Florida wetlands using ERS-1 SAR imagery. Photogramm. Eng. Remote Sens. 1997, 63, 281-291. 
52. Lang, M.W.; Kasischke, E.S. Using C-band synthetic aperture radar data to monitor forested wetland hydrology in Maryland's coastal plain, USA. IEEE Trans. Geosci. Remote Sens. 2008, 46, 535-546. [CrossRef]

53. Schmitt, A.; Brisco, B. Wetland Monitoring Using the Curvelet-Based Change Detection Method on Polarimetric SAR Imagery. Water 2013, 5, 1036-1051. [CrossRef]

54. Moser, L.; Schmitt, A.; Wendleder, A.; Roth, A. Monitoring of the Lac Bam wetland extent using dual-polarized X-band SAR data Remote Sens. Environ. 2016, 8, 302. [CrossRef]

55. Jensen, K.; McDonald, K.; Podest, E.; Rodriguez-Alvarez, N.; Horna, V.; Steiner, N. Assessing L-Band GNSS-reflectometry and imaging radar for detecting sub-canopy inundation dynamics in a tropical wetlands complex. Remote Sens. 2018, $10,1431$. [CrossRef]

56. Rosenqvist, J.; Rosenqvist, A.; Jensen, K.; McDonald, K. Mapping of maximum and minimum inundation extents in the amazon basin 2014-2017 with ALOS-2 PALSAR-2 scan SAR time-series data. Remote Sens. 2020, 12, 1326. [CrossRef]

57. Ramsey, E.; Werle, D.; Suzuoki, Y.; Rangoonwala, A.; Lu, Z. Limitations and Potential of Satellite Imagery to Monitor Environmental Response to Coastal Flooding. J. Coast. Res. 2012, 280, 457-476. [CrossRef]

58. Kim, J.-W.; Lu, Z.; Jones, J.W.; Shum, C.K.; Lee, H.; Jia, Y. Monitoring Everglades freshwater marsh water level using L-band synthetic aperture radar backscatter. Remote Sens. Environ. 2014, 150, 66-81. [CrossRef]

59. Novo, E.M.L.M.; Costa, M.P.F.; Mantovani, J.E.; Lima, I.B.T. Relationship between macrophyte stand variables and radar backscatter at L and C band, Tucuruí reservoir, Brazil. Int. J. Remote Sens. 2002, 23, 1241-1260. [CrossRef]

60. Leck, M.A.; Baldwin, A.H.; Parker, V.T.; Schile, L.; Whigham, D.F. Plant Communities of Tidal Freshwater Wetlands of the Continental USA and Canada. Tidal Freshw. Wetl. 2009, 5, 41-58.

61. Hird, J.N.; DeLancey, E.R.; McDermid, G.J.; Kariyeva, J. Google earth engine, open-access satellite data, and machine learning in support of large-area probabilistic wetland mapping. Remote Sens. 2017, 9, 1315. [CrossRef]

62. Slagter, B.; Tsendbazar, N.-E.; Vollrath, A.; Reiche, J. Mapping wetland characteristics using temporally dense Sentinel-1 and Sentinel-2 data: A case study in the St. Lucia wetlands, South Africa. Int. J. Appl. Earth Obs. Geoinf. 2020, 86, 102009. [CrossRef]

63. Huang, W.; DeVries, B.; Huang, C.; Lang, M.W.; Jones, J.W.; Creed, I.F.; Carroll, M.L. Automated extraction of surface water extent from Sentinel-1 data. Remote Sens. 2018, 10, 797. [CrossRef]

64. Bioresita, F.; Puissant, A.; Stumpf, A.; Malet, J.-P. A Method for Automatic and Rapid Mapping of Water Surfaces from Sentinel-1 Imagery. Remote Sens. 2018, 10, 217. [CrossRef]

65. Ramsey, E.; Rangoonwala, A.; Jones, C.E. Structural classification of marshes with polarimetric SAR highlighting the temporal mapping of marshes exposed to oil. Remote Sens. 2015, 7, 11295-11321. [CrossRef]

66. Jensen, D.; Cavanaugh, K.C.; Simard, M.; Okin, G.S.; Castañeda-Moya, E.; McCall, A.; Twilley, R.R. Integrating imaging spectrometer and synthetic aperture radar data for estimating wetland vegetation aboveground biomass in coastal Louisiana. Remote Sens. 2019, 11, 2533. [CrossRef]

67. Thomas, N.; Simard, M.; Castañeda-Moya, E.; Byrd, K.; Windham-Myers, L.; Bevington, A.; Twilley, R.R. High-resolution mapping of biomass and distribution of marsh and forested wetlands in southeastern coastal Louisiana. Int. J. Appl. Earth Obs. Geoinf. 2019, 80, 257-267. [CrossRef]

68. Bourgeau-Chavez, L.; Endres, S.; Battaglia, M.; Miller, M.E.; Banda, E.; Laubach, Z.; Higman, P.; Chow-Fraser, P.; Marcaccio, J. Development of a bi-national Great Lakes coastal wetland and land use map using three-season PALSAR and Landsat imagery. Remote Sens. 2015, 7, 8655-8682. [CrossRef]

69. San Martín, L.; Morandeira, N.S.; Grimson, R.; Rajngewerc, M.; González, E.B.; Kandus, P. The contribution of ALOS/PALSAR-1 multi-temporal data to map permanently and temporarily flooded coastal wetlands. Int. J. Remote Sens. 2020, 41, 1582-1602. [CrossRef]

70. Whitcomb, J.; Moghaddam, M.; McDonald, K.; Kellndorfer, J.; Podest, E. Mapping vegetated wetlands of Alaska using L-band radar satellite imagery. Can. J. Remote Sens. 2009, 35, 54-72. [CrossRef]

71. Clewley, D.; Whitcomb, J.; Moghaddam, M.; McDonald, K.; Chapman, B.; Bunting, P. Evaluation of ALOS PALSAR Data for High-Resolution Mapping of Vegetated Wetlands in Alaska. Remote Sens. 2015, 7, 7272-7297. [CrossRef]

72. Breiman, L. Random forests. Mach. Learn. 2001, 45, 5-32. [CrossRef]

73. Swarth, C.W.; Delgado, P.; Whigham, D.F. Vegetation Dynamics in a Tidal Freshwater Wetland: A Long-Term Study at Differing Scales. Estuaries Coasts 2013, 36, 559-574. [CrossRef]

74. New York State Department of Environmental Conservation (NYSDEC); Hudson River National Estuarine Research Reserve (HRNERR); Cornell Institute for Resource Information Sciences (Cornell IRIS). Hudson River Estuary Tidal Wetlands 2007. Published by HRNERR and NYSEC. Albany, New York. 2011. Available online: https://gis.ny.gov/gisdata/inventories/details. cfm?DSID=1210 (accessed on 2 June 2020).

75. Gorelick, N.; Hancher, M.; Dixon, M.; Ilyushchenko, S.; Thau, D.; Moore, R. Google Earth Engine: Planetary-scale geospatial analysis for everyone. Remote Sens. Environ. 2017, 202, 18-27. [CrossRef]

76. Tucker, C.J. Red and photographic infrared linear combinations for monitoring vegetation. Remote Sens. Environ. 1979, 8, 127-150. [CrossRef]

77. Prabhakara, K.; Dean Hively, W.; McCarty, G.W. Evaluating the relationship between biomass, percent groundcover and remote sensing indices across six winter cover crop fields in Maryland, United States. Int. J. Appl. Earth Obs. Geoinf. 2015, 39, 88-102. [CrossRef] 
78. Vermote, E.; Justice, C.; Claverie, M.; Franch, B. Preliminary analysis of the performance of the Landsat 8/OLI land surface reflectance product. Remote Sens. Environ. 2016, 185, 46-56. [CrossRef]

79. Zhu, Z.; Wang, S.; Woodcock, C.E. Improvement and expansion of the Fmask algorithm: Cloud, cloud shadow, and snow detection for Landsats 4-7, 8, and Sentinel 2 images. Remote Sens. Environ. 2015, 159, 269-277. [CrossRef]

80. Knight, J.F.; Tolcser, B.P.; Corcoran, J.M.; Rampi, L.P. The effects of data selection and thematic detail on the accuracy of high spatial resolution wetland classifications. Photogramm. Eng. Remote Sens. 2013, 79, 613-623. [CrossRef]

81. R Core Team. R: A Language and Environment for Statistical Computing; R Foundation for Statistical Computing: Vienna, Austria, 2020; Available online: http:/ / www.r-project.org/ (accessed on 2 June 2020).

82. United States Fish and Wildlife Service. Water Chestnut (T. natans). Ecology Risk Screening Summary; U.S. Fish \&Wildlife Service: Washington, DC, USA, 2014.

83. Cornell Institute for Resource Information Sciences (Cornell IRIS); Hudson River National Estuarine Research Reserve (HRNERR); New York State Department of Environmental Conservation (NYSDEC). Hudson River Submerged Aquatic Vegetation 2018. Published by HRNERR and NYSEC. Albany, New York. 2019. Available online: http:/ /gis.ny.gov/gisdata/inventories/details. cfm?DSID $=1350$ (accessed on 2 June 2020).

84. USDA Farm Service Agency, 2021. National Agriculture Imagery Program (NAIP). Available online: https://www.fsa.usda.gov/ programs-and-services/aerial-photography/imagery-programs/naip-imagery/index (accessed on 20 April 2021).

85. Carle, M.V.; Sasser, C.E.; Roberts, H.H. Accretion and Vegetation Community Change in the Wax Lake Delta Following the Historic 2011 Mississippi River Flood. J. Coast. Res. 2015, 31, 569-587. [CrossRef]

86. Sciance, M.B.; Patrick, C.J.; Weller, D.E.; Williams, M.N.; McCormick, M.K.; Hazelton, E.L.G. Local and regional disturbances associated with the invasion of Chesapeake Bay marshes by the common reed P. australis. Biol. Invasions 2016, 18, 2661-2677. [CrossRef]

87. National Audubon Society. Active Delta (Mississippi River Birdsfoot Delta). Available online: https://www.audubon.org/ important-bird-areas/active-delta-mississippi-river-birdsfoot-delta (accessed on 12 September 2016).

88. Ganju, N.K.; Defne, Z.; Kirwan, M.L.; Fagherazzi, S.; D’Alpaos, A.; Carniello, L. Spatially integrative metrics reveal hidden vulnerability of microtidal salt marshes. Nat. Commun. 2017, 8, 14156. [CrossRef]

89. Handley, L.; Wells, C. Comparison of NLCD with NWI Classifications of Baldwin and Mobile Counties, Alabama; United States Geological Survey Report 2009-1058; US Department of the Interior, US Geological Survey: Washington, DC, USA, 2009.

90. Nichols, C. Map Accuracy of National Wetlands Inventory Maps for Areas Subject to Maine Land Use Regulation Commission Jurisdiction; Ecological Services Report R5-94/6; U.S. Fish and Wildlife Service: Hadley, MA, USA, 1994; p. 14.

91. Dabrowska-Zielinska, K.; Budzynska, M.; Tomaszewska, M.; Malinska, A.; Gatkowska, M.; Bartold, M.; Malek, I. Assessment of carbon flux and soil moisture in wetlands applying Sentinel-1 data. Remote Sens. 2016, 8, 756. [CrossRef]

92. Elliton, C.E. Interactions among Hydrology, Sediment and Vegetation in Accreting Wax Lake Delta: Physical and Biogeochemical Implications for Coastal Louisiana Restoration. Master's Thesis, LSU Office of Research and Economic Development, Baton Rouge, LA, USA, 2013.

93. Olliver, E.A.; Edmonds, D.A.; Shaw, J.B. Influence of Floods, Tides, and Vegetation on Sediment Retention in Wax Lake Delta, Louisiana, USA. J. Geophys. Res. Earth Surf. 2020, 125, 1-21. [CrossRef] 